\title{
A BIODEGRADABLE ANTIBIOTIC-IMPREGNATED SCAFFOLD TO PREVENT OSTEOMYELITIS IN A CONTAMINATED IN VIVO BONE DEFECT MODEL
}

\author{
J.S. M'Laren ${ }^{1}$, L.J. White², H.C. Cox ${ }^{2}$, W. Ashraf ${ }^{1}$, C.V. Rahman², G.W. Blunn ${ }^{4}$, A.E. Goodship ${ }^{4}$, R.A. Quirk ${ }^{3}$, \\ K.M. Shakesheff ${ }^{2}$, R. Bayston ${ }^{1}$ and B.E. Scammell ${ }^{1, *}$
}

\author{
${ }^{1}$ University of Nottingham, Academic Orthopaedics, Trauma and Sports Medicine, C Floor, West Block, \\ Queen's Medical Centre, Nottingham, NG7 2UH, UK \\ ${ }^{2}$ Centre for Biomolecular Sciences, University of Nottingham, University Park, Nottingham, NG7 2RD, UK \\ ${ }^{3}$ Locate Therapeutics Ltd, The Sir Colin Campbell Building, Innovation Park, Triumph Road, \\ Nottingham NG7 2TU, UK \\ ${ }^{4}$ Institute of Orthopaedics \& Musculoskeletal Science, UCL, Royal National Orthopaedic Hospital, Brockley Hill, \\ Stanmore, HA7 4LP, UK
}

\begin{abstract}
Open fractures are at risk of serious infection and, if infected, require several surgical interventions and courses of systemic antibiotics. We investigated a new injectable formulation that simultaneously hardens in vivo to form a porous scaffold for bone repair and delivers antibiotics at high concentrations to the local site of infection. Duration of antimicrobial activity against Staphylococcus aureus was determined using the serial plate transfer test. Ultimate compressive strength and porosity of the material was measured with and without antibiotics. The material was evaluated in vivo in an ovine medial femoral condyle defect model contaminated with $S$. aureus. Sheep were sacrificed at either 2 or 13 weeks and the defect and surrounding bone assessed using micro-computed tomography and histology. Antimicrobial activity in vitro persisted for 19-21 days. Sheep with antibiotic-free material and bacteria became infected, while those with antibiotic-containing material and bacteria did not. Similarly, new bone growth was seen in uninoculated animals with plain polymer, and in those with antibiotic polymer with bacteria, but not in sheep with plain polymer and bacteria. The antibiotic-impregnated scaffolds were effective in preventing $S$. aureus infections whilst supporting bone growth and repair. If translated into clinical practice, this approach might reduce the need for systemic antibiotics.
\end{abstract}

Keywords: PLGA; biodegradable scaffold; infection; in vivo; bone ingrowth.

*Address for correspondence:

Brigitte E. Scammell

University of Nottingham

Academic Orthopaedics, Trauma and Sports Medicine

C Floor, West Block, Queen's Medical Centre

Nottingham, NG7 2UH, UK

Telephone Number: +44 1158231115

FAX Number: +44 1158231118

E-mail: b.scammell@nottingham.ac.uk

\section{Introduction}

Even with optimal management, the risk of infection is greater than $30 \%$ in the most severe open fractures, with only 1-2 \% of closed fractures becoming infected (Patzakis and Wilkins, 1989; Giannoudis et al., 2006; Zalavras et al., 2007). Treatment after initial surgical debridement often comprises the implantation and subsequent removal of antibiotic-impregnated beads in parallel with systemic broad-spectrum antibiotics before bone grafting can be carried out (Motsitsi, 2008). This is a lengthy and costly process, with $3.7 \%$ of infections unsuccessfully treated (Ostermann et al., 1995). Current methods of local antibiotic delivery involve the use of non-biodegradable or biodegradable materials that are unsatisfactory for several reasons. Non-biodegradable materials include polymethylmethacrylate (PMMA) preformed beads consisting of gentamicin and antibioticimpregnated PMMA cement. While they deliver high local concentrations of antibiotics, they are not replaced with new bone and require a second surgery for removal (Stańczyk and van Rietbergen, 2004; Gogia et al., 2009). Biodegradable products on the market, for example gentamicin-impregnated collagen sheets and calcium sulphate, degrade too rapidly to support new bone growth (Hing et al., 2007), do not provide structural support (Carson and Bostrom, 2007) and contain only one antibiotic, encouraging development of bacterial resistance (Zhao and Drlica, 2002). A range of aerobic bacteria, in particular Staphylococcus aureus, Enterobacteria, Streptococcus species and anaerobes (Mader et al., 1999) may cause osteomyelitis, with the most commonly used antibiotic, gentamicin, inactive against anaerobic bacteria (Web Ref. 1). In order to extend the antimicrobial spectrum, and to prevent resistance, a combination of at least two antibiotics with different bacterial target sites should be used (Zhao and Drlica, 2002). At the same time, considerations of chemical compatibility, release kinetics and potential for local toxicity, especially to osteoblasts, need to be taken into account. A combination of gentamicin and clindamycin would give activity against most of the expected bacterial contaminants including anaerobes.

Injectable biodegradable scaffolds have many benefits including minimally invasive delivery and the ability to deliver drugs in vitro (Rahman et al., 2012; Gould et al., 2013; Rahman et al., 2013) and drugs, cells and proteins 
locally to the fracture site (Ginty et al., 2008; Kirby et al., 2011). They have also been shown to reduce the length of hospital stay; need for rehabilitation, postoperative morbidity and readmission rate and consequently the associated costs are significantly reduced (Ilan and Ladd, 2003). The scaffolds provide mechanical strength to the wound site and an osteoconductive matrix. Several factors have an effect on bone growth; especially scaffold porosity (Mastrogiacomo et al., 2006), pore size (Karageorgiou and Kaplan, 2005), pore interconnectivity, mechanical strength and degradation rate (Blokhuis et al., 2000). There is a trade-off between porosity and mechanical strength, which is thought to fall ideally within the biological range for human trabecular bone of 50-90\% porosity with pore sizes of at least $100 \mu \mathrm{m}$ (Karageorgiou and Kaplan, 2005) and a compressive strength of 2-12 MPa (Lee and Shin, 2007). The degradation rate of the bone graft material should match the rate of the bone growth for optimal bone regeneration (Vaccaro, 2002; Wenisch et al., 2003).

An injectable material using poly(DL-lactic acid-coglycolic acid) (PLGA), which is a biodegradable synthetic polymer, with a long history of medical use (Anderson and Shive, 1997; Zolnik and Burgess, 2007) was evaluated. The degradation of the polymer particles can be altered by the modification of the lactide:glycolide ratio, the chain length and the addition of plasticisers (Jacobsen and Fritz, 1999). The plasticiser PEG was added to alter the polymer's thermal profile, resulting in the production of thermally sensitive particles. These harden into a solid porous structure at $37^{\circ} \mathrm{C}$, due to particles becoming adhesive and malleable at their glass transition temperature and adhering to each other Dhillon et al., 2011). The hydrophilic PEG begins to leach out of the particles causing a decrease in concentration and a concomitant increase in glass transition temperature, therefore allowing the particles to re-solidify to form a strong porous structure (France and Quirk, 2008). The resulting scaffolds support cell growth, as shown by their ability to support the growth of human mesenchymal stem cells for 7 days (Rahman et al., 2012). Gentamicin sulphate and clindamycin hydrochloride can be suspended in the liquid carrier and then become trapped within the pores of the scaffold as it hardens.

In this study we explored the hypothesis that antibiotic impregnation of the biodegradable scaffold would prevent infection and support new bone growth in a bacterially contaminated bone defect.

\section{Materials and Methods}

\section{Particle production}

Poly (DL-lactic acid-co-glycolic acid) (PLGA 85:15 DLG 4A, molecular weight $56 \mathrm{kDa}$, Lakeshore Biomaterials/ Evonik, Essen, Germany) was melt-blended with poly(ethylene glycol) 400 (PEG 400, Clariant, Leeds, UK) using a heating mantle at $110-120^{\circ} \mathrm{C}$ and a Silverson high shear mixer, to produce a blend of $93.5 \%$ PLGA and $6.5 \%$ PEG 400 (w/w).

The blend was ground into particles, after cooling with liquid nitrogen, using a bench top grinder (F203, Krups,
Liverpool, UK). An AS 200 Sieve Shaker (Retsch, Haan, Germany) was used to collect the 100-200 $\mu \mathrm{m}$ fraction.

The final powder contained $90 \%$ of the blend (PLGA and PEG 400) dry-mixed with $10 \%$ of $100-200 \mu \mathrm{m} \beta$-tricalcium phosphate w/w ( $\beta$-TCP, Plasma Biotal, Buxton, UK). This was then sterilised with electron beam radiation at 25-30 kGy (Isotron, Daventry, UK).

\section{Carrier production}

To form a paste the particles were mixed with $0.5 \%$ medium viscosity sodium carboxymethyl cellulose (CMC, Blanose, Ashland, Covington, KY, USA) dissolved in $0.9 \%$ saline (B. Braun, Sheffield, UK) at a ratio of $1 \mathrm{~g}$ of powder to $0.8 \mathrm{~mL}$ of liquid. The $\mathrm{CMC}$ had a viscosity of 400-800 cps, a substitution range of 1.15-1.45 and a sodium content of $10.5-12 \%$. The CMC solution was previously steam-sterilised at $121{ }^{\circ} \mathrm{C}$ for $15 \mathrm{~min}$. For test samples, the antibiotics were suspended in the CMC solution before mixing with the powder.

\section{Scaffold preparation}

Scaffolds were prepared for strength, porosity and serial plate transfer tests using $6 \mathrm{~mm} \times 12 \mathrm{~mm}$ cylindrical PTFE moulds. After the mould was filled with the polymer paste, it was placed in a sealed polythene bag for $2 \mathrm{~h}$ in a cell culture incubator maintained at $37^{\circ} \mathrm{C}$, to simulate body conditions of temperature and humidity. For strength and porosity testing, the moulds were additionally placed in $0.9 \%$ saline at $37^{\circ} \mathrm{C}$ for $24 \mathrm{~h}$. The 2 and $24 \mathrm{~h}$ time points were selected due to the initial setting and the final hardening of the scaffold, respectively.

\section{In vitro porosity}

After sintering for $24 \mathrm{~h}$ and freeze-drying for $12-18 \mathrm{~h}$, the porosity of the in vitro scaffolds was calculated using both the Archimedes' Principle of Mass Displacement Equation (eqn. 1) and micro-computed tomography.

A high-resolution Skyscan micro X-ray computed tomography system (micro-CT, Skyscan 1174, Skyscan, Kontich, Belgium) was used to determine porosity within the scaffolds. Scanning was carried out at a voltage of $50 \mathrm{kV}$, current of $800 \mathrm{~mA}$ and a voxel resolution of $14.7 \mu \mathrm{m}$. The transmission images were reconstructed using Skyscan supplied software (NRecon).

To distinguish between solid material and porous regions a single threshold value was applied and a second threshold value $(255 / 20)$ was selected to segment the pores from surrounding scaffold material.

$\%$ Porosity $=1-($ BulkDensity $\div$ Particle Density $) \times 100$

\section{Mechanical testing}

Unconstrained uniaxial compression testing was carried out on both antibiotic-impregnated and control scaffolds. A TA.HD+ texture analyser fitted with a Peltier chamber (Stable Microsystems, Godalming, UK) was used with a $10 \mathrm{~mm}$ compression probe, a $50 \mathrm{~kg}$ load cell and a test speed of $0.04 \mathrm{~mm} / \mathrm{sec}$ at $37^{\circ} \mathrm{C}$. Young's modulus and the ultimate compressive strength were calculated. Fifteen min, $2 \mathrm{~h}$ and $24 \mathrm{~h}$ time points were assessed to check scaffold setting time. 


\section{Serial Plate Transfer Test}

The Serial Plate Transfer Test (SPTT) was used to monitor antimicrobial activity and also the duration of antibiotic release from the scaffold material that was to be used in the in vivo study (Bayston et al., 2009).

Plates of Iso-Sensitest Agar (ISA, Oxoid, Basingstoke, UK) were inoculated, using a sterile swab, with a suspension of bacteria ( $S$ aureus) of opacity equivalent to

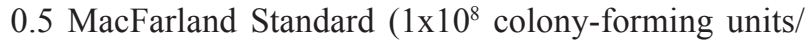
$\mathrm{mL})$. Scaffolds with and without antibiotics were placed in the centre of an agar plate $(n=3)$ and incubated for 18$24 \mathrm{~h}$ at $37^{\circ} \mathrm{C}$. The zones of inhibition (zone diameter minus scaffold diameter in $\mathrm{mm}$ ) were measured using digital callipers. Scaffolds were transferred daily to a fresh seeded plate, ensuring that the same scaffold surface was in contact with the agar, until a zone of inhibition was no longer seen. Any antibiotic impregnated scaffolds that ceased to produce a ZOI were split in half lengthways, placed onto seeded agar plates with the flat surface in contact with the agar and incubated overnight at $37^{\circ} \mathrm{C}$, to ensure that no further antibiotics were being released.

\section{Test bacterium}

The strain of $S$. aureus used in this study was a clinical isolate (F2789) obtained from an infected human knee arthroplasty at revision surgery. Characterisation was carried out by conventional methods: gram stain, catalase production, DNAse production, antibiotic susceptibilities (in accordance with the British Society for Antimicrobial Chemotherapy Guidelines (Web Ref. 2)), biochemical profiling (API, BioMérieux, Basingstoke, UK) and minimum inhibitory concentration (MIC, Etest, AB Biodisk, Solna, Sweden).

\section{Antibiotics}

The antibiotic combination tested was $4 \%$ gentamicin sulphate w/v (Sigma-Aldrich) and $2.5 \%$ clindamycin hydrochloride w/v (Pfizer, Tadworth, UK). These antibiotic concentrations were selected as they are similar to what is already in routine use in bone cements, for example Refobacin Revision Cement (BIOMET, Malmö, Sweden) and Copal $\mathrm{G}+\mathrm{C}$ Revision Cement (Heraeus Medical, Newbury, UK), and together cover the majority of bacteria involved in osteomyelitis.

The antibiotics were suspended in the carrier $(0.5 \%$ medium viscosity CMC dissolved in $0.9 \%$ saline) that was used to form the polymer paste.

\section{Scaffold drug content}

The total antibiotic content was measured in crushed antibiotic impregnated scaffolds that had been releasing antibiotics on an SPTT for up to 21 days. Clindamycin was measured using High Performance Liquid Chromatography (HPLC) whilst gentamicin was detected with an ADVIA Centaur Gentamicin assay (Siemens, Erlangen, Germany).

For the detection and quantification of Clindamycin hydrochloride, RP-HPLC analysis was performed on an Agilent 1100 HPLC machine with a variable wavelength UV detector (HPLC - UV) (Agilent Technologies, Berkshire, UK) connected to a Chemstation operating software system. Chromatographic separations were performed on an Eclipse XDB-C8 (5 $\mu \mathrm{m}$, internal diameter (i.d.) $4.6 \mathrm{~mm} \times 150 \mathrm{~mm}$ ) column (Agilent Technologies). Column temperature was $40{ }^{\circ} \mathrm{C}$, the volume of injection was $100 \mu \mathrm{L}$ and the flow rate was $1.0 \mathrm{~mL} / \mathrm{min}$.

A gradient was used to detect clindamycin and the mobile phase consisted of aqueous sodium dihydrogen phosphate (15 mM, pH 2.5, Sigma-Aldrich) with $10 \%$ acetonitrile and methanol (Fisher Scientific, Loughborough, UK).

Gentamicin levels were detected using the ADVIA Centaur Gentamicin assay, which is a competitive immunoassay using direct, chemiluminescent technology. The sample competes with acridinium ester-labelled gentamicin derivative in the reagent for a limited amount of monoclonal mouse anti-gentamicin antibody, which is coupled to paramagnetic particles. There is an inverse relationship between the amount of gentamicin and the amount of relative light units detected by the system.

\section{In vivo model and surgery}

Thirty female non-pregnant skeletally mature (age 4-5 years, weight 53-74 kg) English Mule sheep were used. All procedures were carried out in compliance with United Kingdom Home Office regulations (Animal Scientific Procedures Act, Web Ref. 3). Animals were screened, to ensure good physical condition and were acclimatised to the new environment for a minimum of 7 days prior to surgery. After surgery, animals were housed in individual pens for 4 days and then they were housed in a group barn. At two weeks, the sutures were removed and the sheep were put out to pasture. Prior to surgery food was withheld for a minimum of $12 \mathrm{~h}$, but water was available ad libitum. Sheep were assigned randomly to 5 different treatment groups (Table 1). These were an infection and

Table 1. Different treatments for the 5 groups of sheep.

\begin{tabular}{|c|c|c|c|c|c|}
\hline & $\begin{array}{c}\text { Group } \\
\mathbf{1}(\boldsymbol{n}=\mathbf{6})\end{array}$ & $\begin{array}{c}\text { Group } \\
\mathbf{2}(\boldsymbol{n}=\mathbf{6})\end{array}$ & $\begin{array}{c}\text { Group } \\
\mathbf{3}(\boldsymbol{n}=\mathbf{6})\end{array}$ & $\begin{array}{c}\text { Group } \\
\mathbf{4}(\boldsymbol{n}=\mathbf{6})\end{array}$ & $\begin{array}{c}\text { Group } \\
\mathbf{5}(\boldsymbol{n}=\mathbf{6})\end{array}$ \\
\hline $\begin{array}{c}\text { Bacteria added } \\
\text { at surgery }\end{array}$ & S aureus (F2789) & S aureus (F2789) & None & None & S aureus (F2789) \\
\hline $\begin{array}{c}\text { Antibiotics } \\
\text { within scaffold }\end{array}$ & None & $\begin{array}{c}4 \% \text { Gentamicin }+ \\
2.5 \% \text { Clindamycin }\end{array}$ & None & None & $\begin{array}{c}4 \% \text { Gentamicin }+ \\
2.5 \% \text { Clindamycin }\end{array}$ \\
\hline $\begin{array}{c}\text { Sacrifice time- } \\
\text { point }\end{array}$ & 2 weeks & 2 weeks & 2 weeks & 13 weeks & 13 weeks \\
\hline
\end{tabular}


a

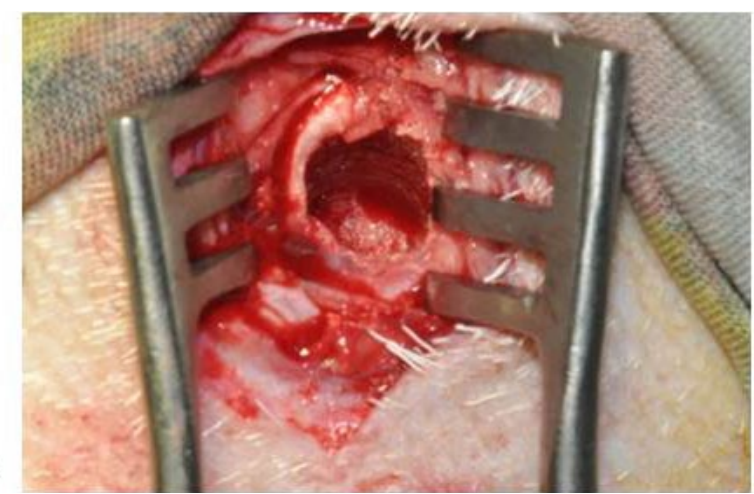

b

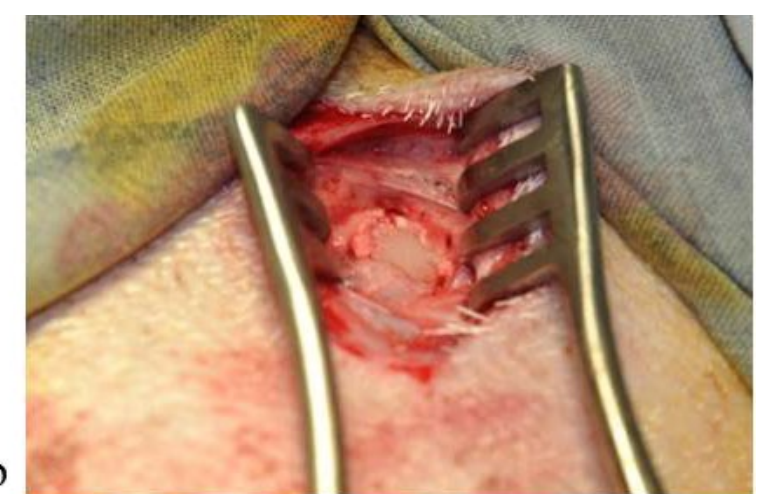

Fig. 1. (a) Image of defect drilled into the femoral condyle of a sheep. (b) Defect filled with scaffold material.

scaffold group sacrificed at 2 weeks, a scaffold only group sacrificed at 2 weeks and 13 weeks and an infection and scaffold with antibiotics group sacrificed at 2 and 13 weeks.

The sheep were pre-medicated intramuscularly with $2 \%$ Rompun $(0.1 \mathrm{mg} / \mathrm{kg}$ Xylazine, Bayer, Newbury, UK). Anaesthesia was induced with Ketaset (Ketamine, $2 \mathrm{mg}$ / $\mathrm{kg}$, Fort Dodge Animal Health Ltd, Southampton, UK) and 2.5 mg Hypnovel (Midazolam, Roche Products, Welwyn Garden City, UK), and then maintained with $2 \%$ Isoflurane (Abbott Laboratories, Maidenhead, UK) in $100 \%$ oxygen. Pre- and post-operative analgesia was given by means of sustained release Durogesic $75 \mu \mathrm{g} / \mathrm{hr}$ patches (Fentanyl, 2 patches $12 \mathrm{~h}$ before surgery and 2 patches $60 \mathrm{~h}$ after surgery, Janssen-Cilag, Saunderton, UK). No prophylactic antibiotics were given either pre- or post-operatively, as this would have invalidated the results. For surgery, the animals were placed in left lateral recumbency to access the medial aspect of the left hind leg. The area was then clipped and prepared using aqueous povidone iodine antiseptic solution (Vetasept, Medivet Professional, Hayes, UK), with an antiseptic swab covering the site until surgery commenced. Once in theatre, the area was thoroughly washed with Hydrex chlorhexidine (Ecolab, Swindon, UK).

The surgical site was incised and a drill hole was made in the cancellous bone of the medial femoral condyle in the left hind leg. The cylindrical hole was $8 \mathrm{~mm}$ diameter $\mathrm{x} 15 \mathrm{~mm}$ deep and created by drilling a pilot hole which was enlarged using a custom calibrated reamer to create a standardised defect (Fig. 1a). In the ovine cancellous bone defect model a critical size defect has been published at a diameter of 5.1-10 mm (Nuss et al., 2006; Bodde et al., 2007; Pearce et al., 2007; van der Pol et al., 2010), and a height of 10-15 mm (Walsh et al., 2003; Patel et al., 2005; Nuss et al., 2006; van der Pol et al., 2010; Ding et al., 2012) within which our defect lies. Culture swabs were taken after the initial skin incision and bone was also taken from within the defect to ensure that the sheep were free of infection at the time of surgery. In scaffold-only sheep, the defect was dried using a sterile swab and the scaffold material (approximately $0.75 \mathrm{~g}$ ) was lightly packed into the defect (Fig. 1b). For the infection groups $20 \mu \mathrm{L}$ of a 2 x $10^{6} \mathrm{cfu} / \mathrm{mL}$ suspension (40,000 cfu) of $S$. aureus (F2789) in sterile phosphate buffered saline (Oxoid) was inoculated into the defect, before packing with scaffold material (approximately $0.75 \mathrm{~g}$ of scaffold either with or without $0.03 \mathrm{~g}$ gentamicin sulphate and $0.019 \mathrm{~g}$ of clindamycin hydrochloride). The subcutaneous tissue was closed using resorbable material (Vicryl 2-0, Ethicon, Kirkton, UK), whilst skin was closed with non-absorbable nylon sutures (Ethilon 0, Ethicon). A moisture vapour-permeable spray dressing (Opsite, Smith \& Nephew Healthcare, Hull, UK) was then applied over the wound to protect it.

The sacrifice time points were 2 weeks and 13 weeks. The 2-week time point was chosen in order to ensure that a localised infection had been created and also that the antibiotics were effective when combined with the scaffold material. By 13 weeks, it was expected that significant bone growth should have occurred due to the rate of bone remodelling and also the degradation rate of the scaffold material. The sheep were sacrificed using an overdose of barbiturate (Pentobarbital solution $20 \%, 0.7 \mathrm{mg} / \mathrm{kg}$, Pharmasol, Andover, UK). Immediately before sacrifice, intravenous blood samples were taken for aerobic and anaerobic culture. After sacrifice, tissue removal was carried out aseptically. Swabs, soft tissue and a sample from within the defect were collected for culture and histological processing. The femoral condyle was then removed and split using a saw with saline irrigation. The two halves were then fixed in $10 \%$ neutral buffered formalin solution (NBF, Sigma-Aldrich), for $48 \mathrm{~h}$ at room temperature.

\section{Culture of blood and tissue samples}

Swabs were plated onto blood agar plates (Oxoid), and incubated aerobically and anaerobically for up to $48 \mathrm{~h}$. The blood samples were inoculated into blood culture vials (BD Bactec ${ }^{\mathrm{TM}}$ Lytic/10 Anaerobic F and Plus+ Aerobic F, Oxford, UK) and incubated for 7 days at $37^{\circ} \mathrm{C}$. A sample was then taken from each bottle and plated on blood agar plates for incubation aerobically and anaerobically for up to 7 days. Bone and tissue samples were vortexed in PBS and the suspension plated onto blood agar, and incubated aerobically and anaerobically for up to $48 \mathrm{~h}$. If bacterial growth occurred isolates were characterised to compare with the inoculum.

\section{Micro-computed tomography}

A high-resolution Skyscan micro X-ray computed tomography system (micro-CT, Skyscan 1174) was used to 
Fig. 2. The duration of antimicrobial activity of scaffolds containing $4 \%$ gentamicin sulphate and $2.5 \%$ clindamycin hydrochloride, tested against $S$. aureus (F2789).

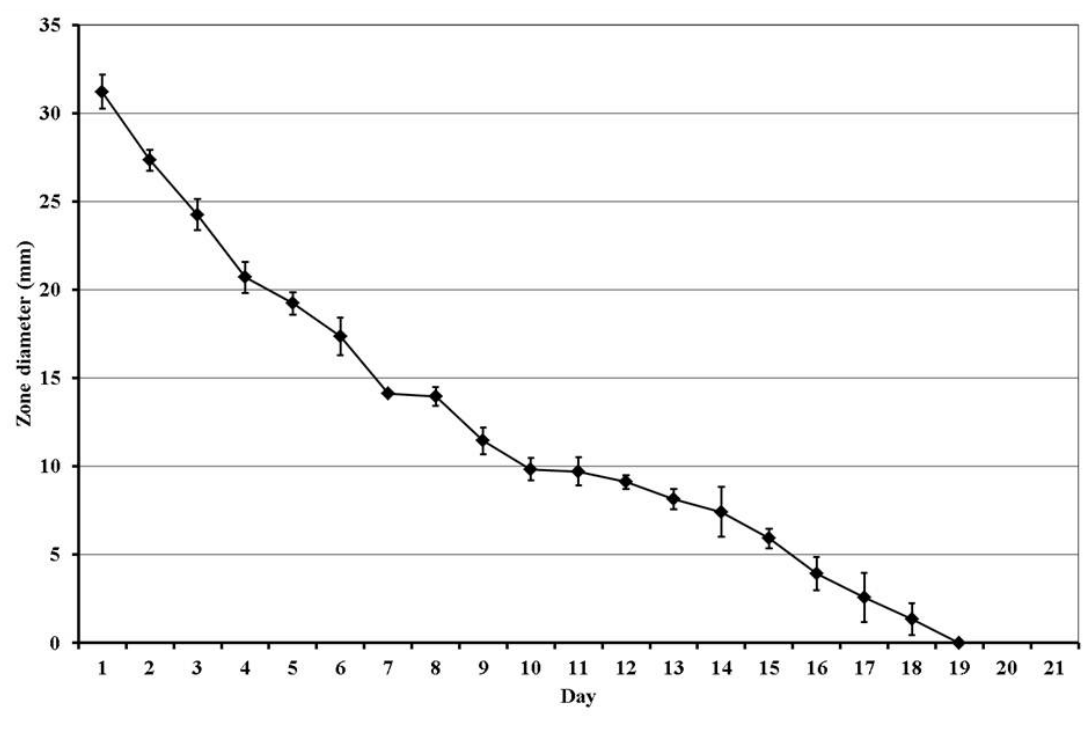

determine bone ingrowth, porosity, pore size and trabecular thickness within femoral condyles. After fixing in $10 \%$ $\mathrm{NBF}$ for $48 \mathrm{~h}$ at room temperature, bone was wrapped in cling film to prevent the sample from drying out and then mounted on the stage within the imaging system. Due to sample size and type, scanning was carried out at a voltage of $50 \mathrm{kV}$, current of $800 \mu \mathrm{A}$ and a voxel resolution of $32.4 \mu \mathrm{m}$. A $0.75 \mu \mathrm{m}$ aluminium filter was also applied. The transmission images were reconstructed using Skyscan supplied software (NRecon).

To distinguish between solid material and porous regions, a single threshold value was applied and a second threshold value $(255 / 75)$ was selected to segment bone from surrounding tissue. Background noise in the images was reduced, by removing black and white speckles of less than 100 voxels. Analysis of bone volume was carried out on a set volume of interest of $5 \times 10^{10} \mu \mathrm{m}^{3}$ which was located $5 \mathrm{~mm}$ from the top of the defect and against the internal edge of the drilled defect. Quantitative analysis of porosity and pore architecture was obtained using direct morphometry calculations in the Skyscan CTAn software package.

\section{Bone histology}

The femoral condyle was fixed in $10 \% \mathrm{NBF}$ solution for $48 \mathrm{~h}$ at room temperature. One half of the condyle was then placed in $10 \%$ ethylenediaminetetraacetic acid (EDTA, Sigma Aldrich) for decalcification. At two-weekly intervals, the bone samples were placed in a faxitron cabinet X-ray system (Model 43855C, Faxitron Bioptics, Tucson, AZ, USA) to assess the level of decalcification. This was judged to be complete at 26 weeks, after no mineralised bone could be detected by the faxitron.

Samples were soaked in a $30 \%$ sucrose solution (Sigma-Aldrich) for $24 \mathrm{~h}$ and then OCT embedding medium (Sakura Finetek UK, Thatcham, UK) for a further $24 \mathrm{~h}$ before cryosectioning. Samples were mounted on cryostat chucks using OCT embedding medium. The sections were cut at -16 to $-18{ }^{\circ} \mathrm{C}$ on a Leica CM1300 (Leica Microsystems, Milton Keynes, UK). The CryoJane $^{\circledR}$ Tape Transfer System (Leica Microsystems) was used to collect the sections. A cold tape window was placed on the exposed block face and pressed down with a roller. A tungsten carbide blade was used without the antiroll plate to give $20 \mu \mathrm{m}$ sections. The tape-mounted sections were then placed section downward onto a $4 \mathrm{x}$ adhesive coated slide and rolled to ensure contact. The slide was then cured with a UV lamp, and the tape window removed.

Sections were then stained with a Modified Tetrachrome Method (Ralis and Watkins, 1992), which involves staining with Weigert's haematoxylin, aniline blue, ponceau mixture and picro-orange. A Nanozoomer (Nanozoomer 2.0 HT, Hamamatsu, Hamamatsu, Japan) was used to image the entire sections at 20x and 40x magnification, and viewed using the NanoZoomer Digital Pathology program. The number of specimens evaluated per group was- Group 1 =1; Group 2 = 3; Group 3=3; Group 4=6; Group $5=6$. Further images were taken using a Qimaging MicroPublisher 3.3RTV camera attached to Leica DM4000 B microscope and accompanying software (OpenLab).

\section{Soft tissue histology}

Soft tissue samples were fixed in $10 \%$ NBF, processed into paraffin wax and stained with Weigert's Haematoxylin and Eosin.

\section{Statistical analysis}

Statistical analysis was carried out using one-way analysis of variance (ANOVA, Minitab ${ }^{\circledR}$ 16.1.0, Coventry, UK). $p$-values of $\leq 0.05$ were considered to be significant. A Fisher's Least Significant Difference post-hoc test was used to investigate individual differences.

\section{Results}

\section{Micro-organism characterisation and sensitivities}

The API profile of F2789 was 6336151 and the numerical antibiogram (Bayston et al., 2009) was 44004. This showed that F2789 was a strain of $S$. aureus susceptible to, amongst others, gentamicin and clindamycin. The minimum inhibitory concentrations (MIC) were $0.094 \mathrm{mg} / \mathrm{L}$ for gentamicin and $0.064 \mathrm{mg} / \mathrm{L}$ for clindamycin. 
Fig. 3. Total gentamicin and clindamycin content $(\mathrm{mg} / \mathrm{L})$ of scaffolds determined by immunoassay and HPLC respectively.

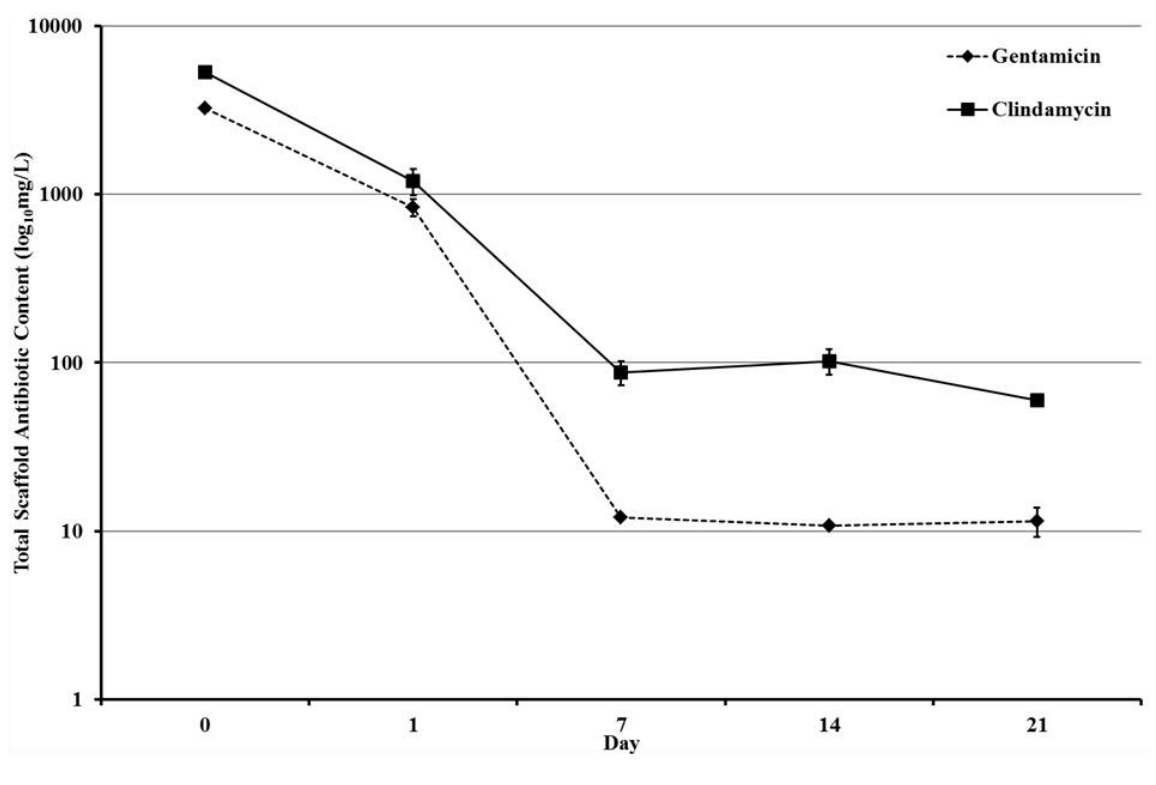

\section{Serial Plate Transfer Test (SPTT)}

Antimicrobial activity declined steadily over a $19 \pm 2$ day period, as can be seen in Fig. 2. No zones of inhibition were observed around scaffolds that were not impregnated with antibiotics. The bacteria did not become resistant to the antibiotic combination over the duration of the release.

\section{Drug content of scaffold (Fig. 3)}

The total content of both gentamicin and clindamycin within scaffolds show a significant drop over the 21 day period, with most of the antibiotics released over the first 7 days. Less than $1 \%$ of the antibiotics were remaining at 21 days.

The lower than expected level of gentamicin is possibly due to the potency of the antibiotics. Gentamicin sulphate has a potency of $590 \mu \mathrm{g} / \mathrm{mg}$, whilst the potency of clindamycin is $900 \mu \mathrm{g} / \mathrm{mg}$.

\section{Mechanical properties}

Compression testing of scaffolds was carried out after $15 \mathrm{~min}, 2 \mathrm{~h}$ and $24 \mathrm{~h}$ of sintering both with and without antibiotic combination. The maximum compressive strength and Young's Modulus increased significantly from a 15 min sinter to a $24 \mathrm{~h}$ sinter in all groups ( $p=0.010$ and $p=0.012$, respectively). Within each time point, there were no differences in the strength of scaffolds with and without antibiotics (Fig. 4 and 5).

To assess porosity the scaffolds were sintered for $24 \mathrm{~h}$ and analysed using both micro-computed tomography and the Archimedes Mass Displacement Equation. The scaffolds had a significantly higher value using the
Archimedes equation as the micro-CT scanning resolution used precluded the detection of microporosity within the scaffolds. There were no significant differences between scaffold porosity within methods, either with or without antibiotics (Table 2).

\section{In vivo study (Table 3)}

The sheep model was selected, as sheep have been used in the study of numerous musculoskeletal conditions and diseases including biomaterial evaluation (Martini et al., 2001; Nuss et al., 2006). Although sheep cortical bone has fewer Haversian canals than human bone, the rate of bone healing approximates human values, with a similar pattern of bone ingrowth into porous implants over time (Pearce et al., 2007).

Group 1 sheep that were inoculated with bacteria and that did not receive antibiotics in the scaffold showed a significantly greater weight loss than the sheep in Groups $2-5(p \leq 0.001)$ and required analgesia for the duration of the study to alleviate lameness. Samples (approximately $1 \mathrm{~mm}^{3}$ ) and swabs collected from within the defect and surrounding soft tissue contained approximately $10^{5} \mathrm{cfu}$ of bacteria per total sample, which were indistinguishable from the original strain (F2789) on re-characterisation using biochemical profiling and antibiograms. In all groups, no bacteria were cultured from the blood - which confirmed that the infection was localised to the bony defect and surrounding area, and was not systemic.

The defects in Groups 2 and 5 were inoculated with S. aureus, but filled with antibiotic-impregnated scaffold material. At both sacrifice time points no bacteria were

Table 2. In vitro porosity results.

\begin{tabular}{|c|c|c|}
\hline \multirow{2}{*}{} & \multicolumn{2}{|c|}{ Method of porosity analysis (\%) \pm SD } \\
\cline { 2 - 3 } & $\begin{array}{c}\text { Archimedes' Principle of Mass } \\
\text { Displacement Equation }\end{array}$ & Micro-computed tomography \\
\hline Scaffold without antibiotics $(\boldsymbol{n}=\mathbf{4})$ & $56.68 \pm 3.13$ & $29.12 \pm 7.26$ \\
\hline Scaffold with antibiotics $(\boldsymbol{n}=\mathbf{4})$ & $54.36 \pm 3.20$ & $33.03 \pm 8.55$ \\
\hline
\end{tabular}


Table 3. Results from the in vivo study.

\begin{tabular}{|c|c|c|c|c|c|}
\hline & $\begin{array}{c}\text { Group 1 } \\
(\boldsymbol{n}=\mathbf{6}) \\
\text { Bacteria and } \\
\text { control scaffold } \\
(\mathbf{2} \text { week sacrifice) }\end{array}$ & $\begin{array}{c}\text { Group 2 } \\
(\boldsymbol{n}=\mathbf{6}) \\
\text { Bacteria and } \\
\text { antibiotic } \\
\text { impregnated } \\
\text { scaffold } \\
(\mathbf{2} \text { week sacrifice) }\end{array}$ & $\begin{array}{c}\text { Group 3 } \\
(\boldsymbol{n}=\mathbf{6}) \\
\text { Scaffold only } \\
\text { control } \\
(\mathbf{2} \text { week sacrifice) }\end{array}$ & $\begin{array}{c}\text { Group 4 } \\
(\boldsymbol{n}=\mathbf{6}) \\
\text { Scaffold only } \\
\text { control } \\
(\mathbf{1 3} \text { week sacrifice) }\end{array}$ & $\begin{array}{c}\text { Group 5 } \\
(\boldsymbol{n}=\mathbf{6}) \\
\text { Bacteria and } \\
\text { antibiotic } \\
\text { impregnated } \\
\text { scaffold } \\
\text { (13 week sacrifice) }\end{array}$ \\
\hline $\begin{array}{c}\text { Pain relief } \\
\text { post-operatively }\end{array}$ & 2 weeks & 3 days & 3 days & 3 days & 3 days \\
\hline $\begin{array}{c}\text { Lameness, } \\
\text { swelling and } \\
\text { increased } \\
\text { respiration rate }\end{array}$ & Yes & No & No & No & No \\
\hline $\begin{array}{c}\text { Weight change at } \\
\text { sacrifice }\end{array}$ & $-7.8 \mathrm{~kg}$ & $+6.2 \mathrm{~kg}$ & $+5.8 \mathrm{~kg}$ & $+8.8 \mathrm{~kg}$ & $+14.3 \mathrm{~kg}$ \\
\hline $\begin{array}{c}\text { Bacteria present at } \\
\text { sacrifice }\end{array}$ & Saureus $(\mathrm{F} 2789)$ & None & None & None & None \\
\hline
\end{tabular}

Fig. 4. The Young's Modulus of scaffolds containing antibiotics (4\% gentamicin $\mathrm{sulphate}$ and $2.5 \%$ clindamycin hydrochloride) after sintering for $15 \mathrm{~min}$, $2 \mathrm{~h}$ or $24 \mathrm{~h}$.

Fig. 5. The ultimate compressive strength of scaffolds containing antibiotics (4 \% gentamicin sulphate and $2.5 \%$ clindamycin hydrochloride) after sintering for $15 \mathrm{~min}$, $2 \mathrm{~h}$ or $24 \mathrm{~h}$.
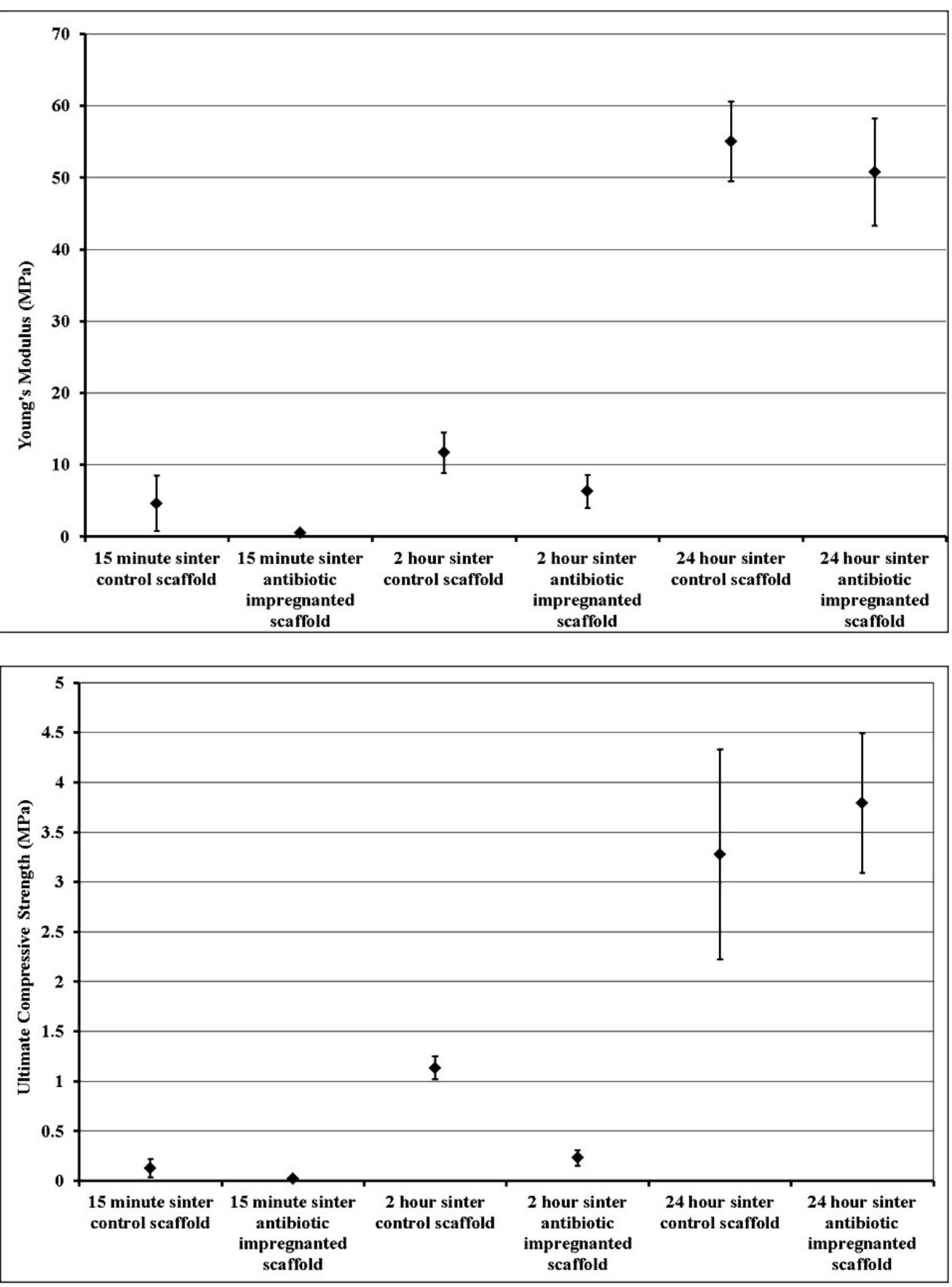

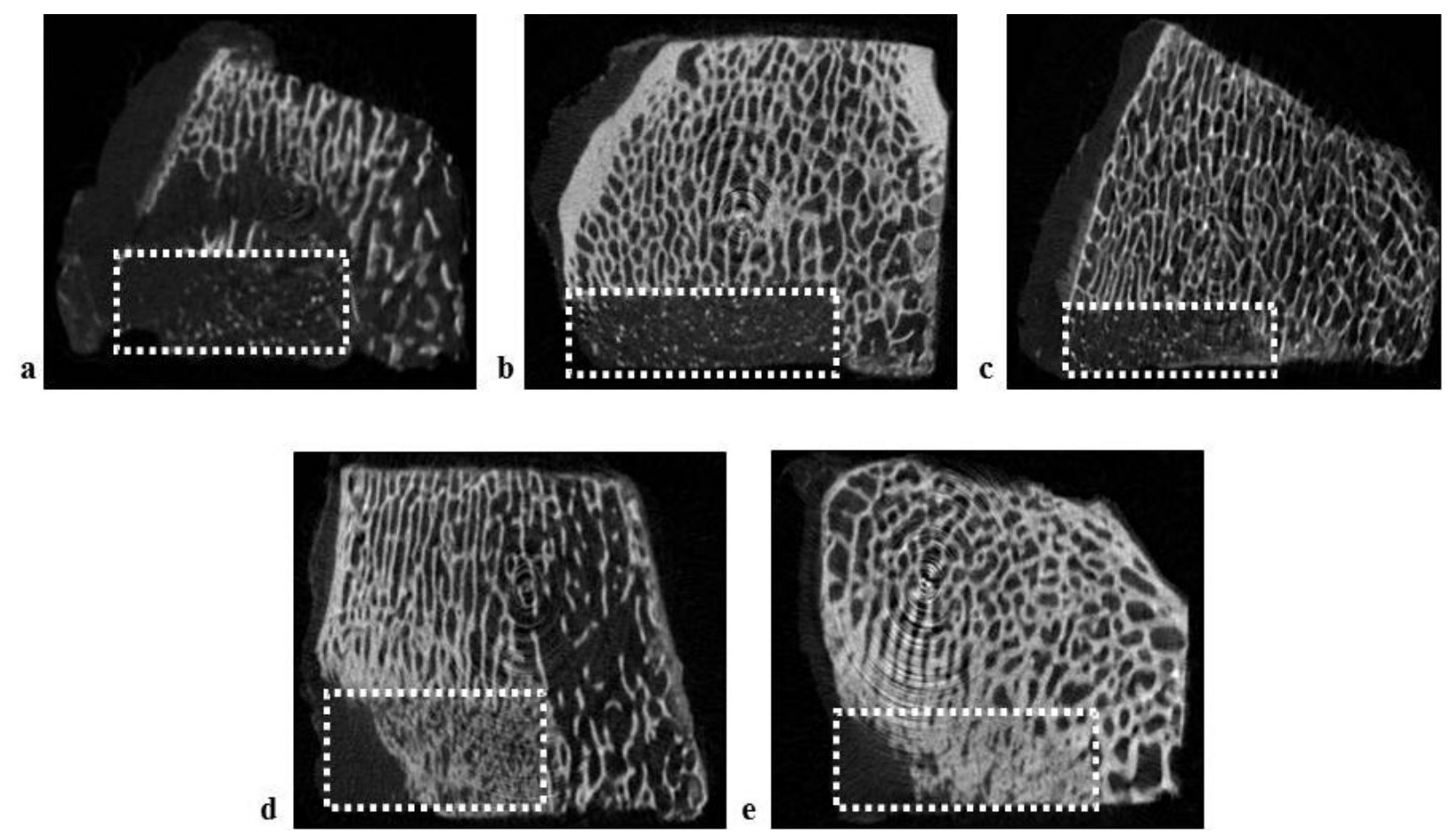

Fig. 6. Micro-CT images of bone defects (half of defect 4 x $15 \mathrm{~mm}$ ) with dotted line depicting the defect site. (a) Defect from the bacteria with antibiotic-free scaffold group (Group 1) showing bone lysis caused by the infection. The $10 \%$ ceramic component can be seen as speckling within the defect, although in this group the product has been poorly retained. (b) Defect from sheep that received bacteria and the antibiotic-impregnated material and sacrificed at 2 weeks (Group 2). (c) Defect from control sheep sacrificed at 2 weeks (Group 3) showing clear edge of a fully packed defect and $10 \%$ ceramic composition of the scaffold material. (d) Control sheep sacrificed at 13 weeks (Group 4) and (e) defect from sheep sacrificed at 13 weeks with bacteria and antibiotic-impregnated scaffold (Group 5) with new bone filling the defect space.

found in the defect or surrounding tissue. Group 3 and 4 sheep had defects filled with control scaffold material and were not inoculated with bacteria. There was no significant difference in weight gained in Groups 2-5, and these sheep required only minimal analgesia.

\section{Micro-computed tomography (micro-CT) (Figs. 6 and 7 , and Table 4)}

The introduction of $S$. aureus and control scaffold without antibiotics lowered bone volume in the area surrounding the defect, compared to sheep that received S. aureus and the antibiotic-impregnated scaffold. This was due to the bone infection breaking down the surrounding bone, and the expulsion of the scaffold material during harvesting (Fig. 6a).

There was no significant difference in bone growth between sheep sacrificed at 2 weeks with (Group 2, Fig. $6 b)$ or without antibiotic-containing scaffold (Group 3, Fig. 6c), or sheep sacrificed at 13 weeks without (Group 4, Fig. 6d) or with antibiotic-containing scaffold (Group 5 , Fig. 6e). The edge of the defect was clearly visible in Figs. 6b-6e, with new bone visible in Figs. 6d and 6e.

Sheep sacrificed at 13 weeks had significantly more bone than sheep sacrificed at 2 weeks $(p \leq 0.001)$. There was no significant difference in the bone fill of defects in any group at 2 weeks. At 13 weeks the defect fill in sheep that received the antibiotic-free scaffold was
$68.4 \pm 13.0 \%$ and sheep that received the antibiotic impregnated material and sacrificed at 13 weeks (Group 5) were not significantly different and had a defect fill of $53.8 \% \pm 17.2 \%$ (Fig. 7).

At 13 weeks no scaffold material remained within the defects, as it had fully degraded. Therefore, the porosity and pore sizes of the scaffold material in vivo were calculated from sheep sacrificed at 2 weeks with (Group 2) and without antibiotics (Group 3) (Table 4). There was no significant difference in the initial percentage porosity of the scaffold material with and without antibiotics, which was $24.2 \pm 9.5 \%$ and $26.4 \pm 5.1 \%$, respectively. Scaffold pore size was not significantly different between Group $2(201.2 \pm 21.4 \mu \mathrm{m})$ and Group $3(186.2 \pm 23.9 \mu \mathrm{m})$. The

Table 4. The porosity and pore size of the scaffold material within the bone defect of a sheep at 2 weeks.

\begin{tabular}{|c|c|c|}
\hline & Porosity (\%) \pm SD & Pore size $(\boldsymbol{\mu m}) \pm$ SD \\
\hline $\begin{array}{c}\text { Group 2 } \\
\text { (Bacteria and } \\
\text { antibiotic } \\
\text { impregnated } \\
\text { scaffold, } \boldsymbol{n}=\mathbf{6})\end{array}$ & $24.21 \pm 9.46$ & $201.22 \pm 21.44$ \\
\hline $\begin{array}{c}\text { Group 3 } \\
\text { (Scaffold only } \\
\text { control, } \boldsymbol{n}=\mathbf{6})\end{array}$ & $26.40 \pm 5.10$ & $186.16 \pm 23.91$ \\
\hline
\end{tabular}


Fig. 7. Percentage bone fill of a specific volume of interest within the bone defect.
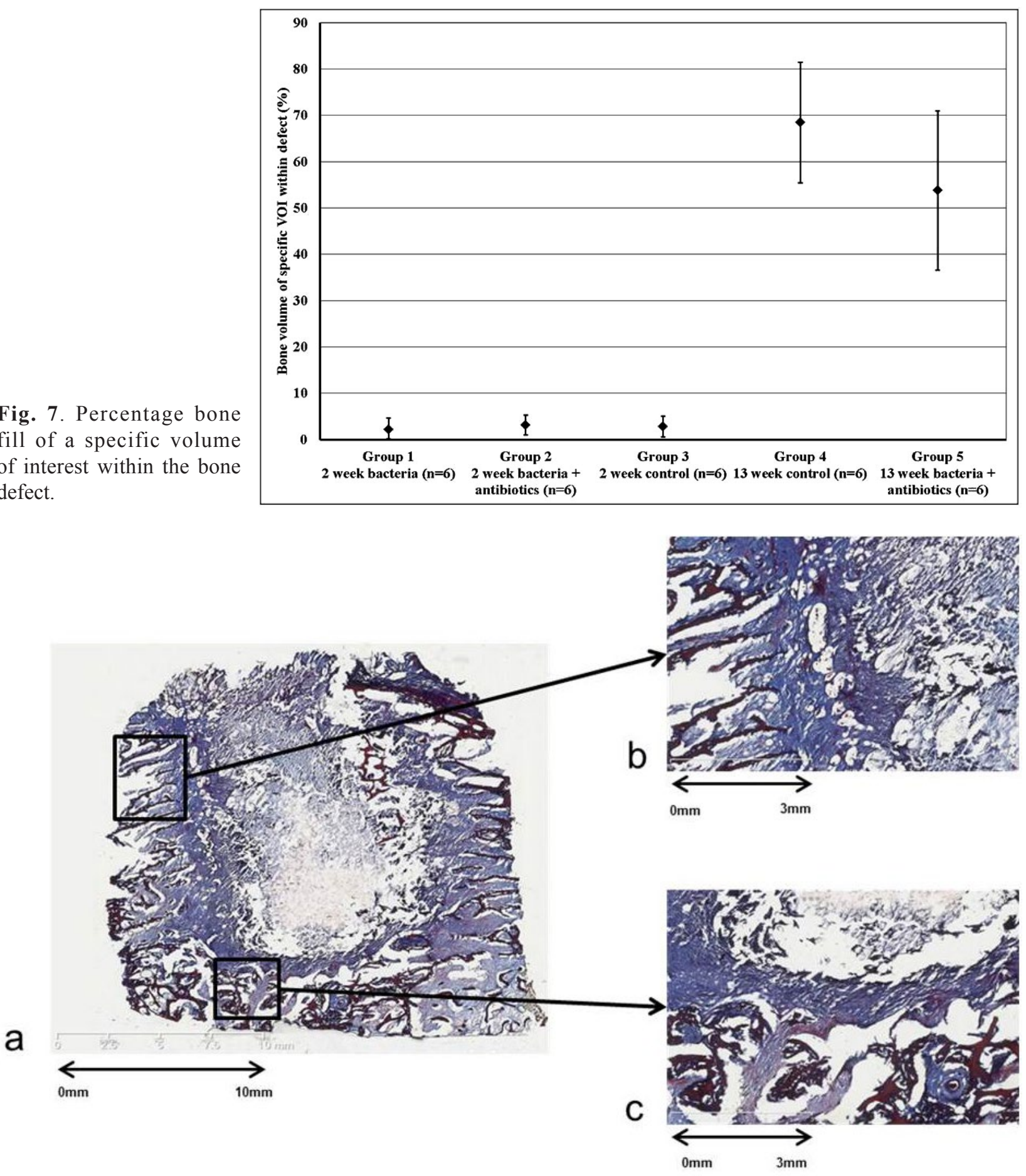

Fig. 8. Ralis tetrachrome staining within a bone defect in the femoral condyle of a sheep that was infected and did not receive antibiotics (Group 1) and sacrificed at 2 weeks. The defect is partially filled with the scaffold material. Sections b (originally, 1.25x magnification) and c (originally, 1.25x magnification) show the fibrous tissue (blue) that has formed due to the bone infection and the bone that is being broken down (red/black).

porosity for both in vivo and in vitro scaffolds was not significantly different when scanned using micro-CT (Tables 2 and 4).

\section{Bone histology}

A modified tetrachrome method (Ralis and Watkins, 1992) was employed to detect the different structures in the harvested femoral condyles.
Group 1 (Bacteria and control scaffold at 2 weeks, Fig. $8)$. Bone surrounding the defect had broken down due to the infection, and fragments were filling the defect space, which was left empty when the scaffold material was not retained at sacrifice. A large amount of fibrous tissue could be seen filling the defect.

Groups 2 (2 week sacrifice with bacteria and antibiotic impregnated scaffold, Fig. 9) and 3 (2 week scaffold 


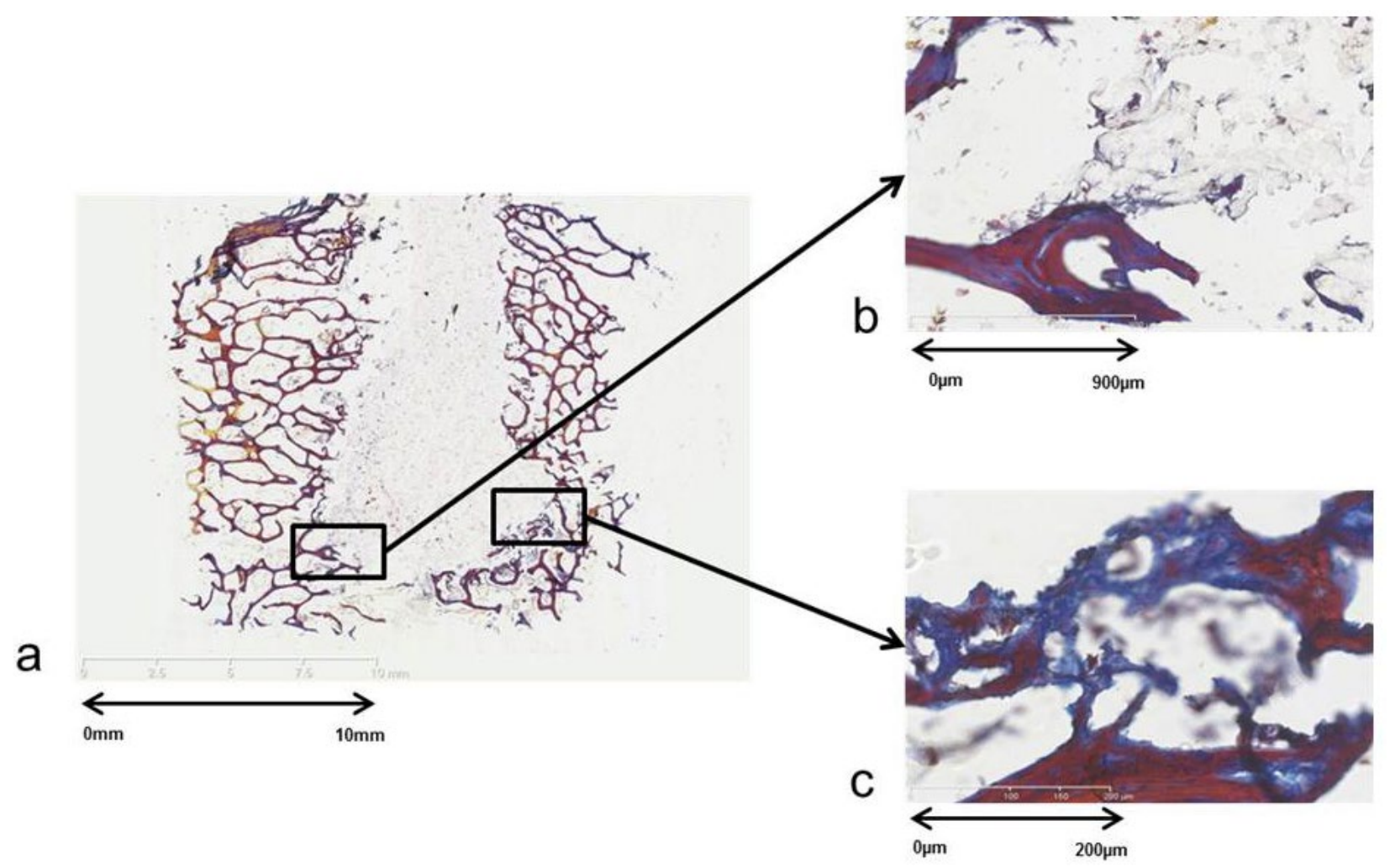

Fig. 9. Ralis tetrachrome staining within a bone defect in the femoral condyle of a sheep sacrificed at 2 weeks with bacteria and antibiotic impregnated scaffold (Group 2). Section b (originally, 1.25x magnification) shows the polymer in contact with the edge of the bone defect and c (originally, 20x magnification) shows areas of osteoid (dark blue) which will in turn lead to new bone formation.

a

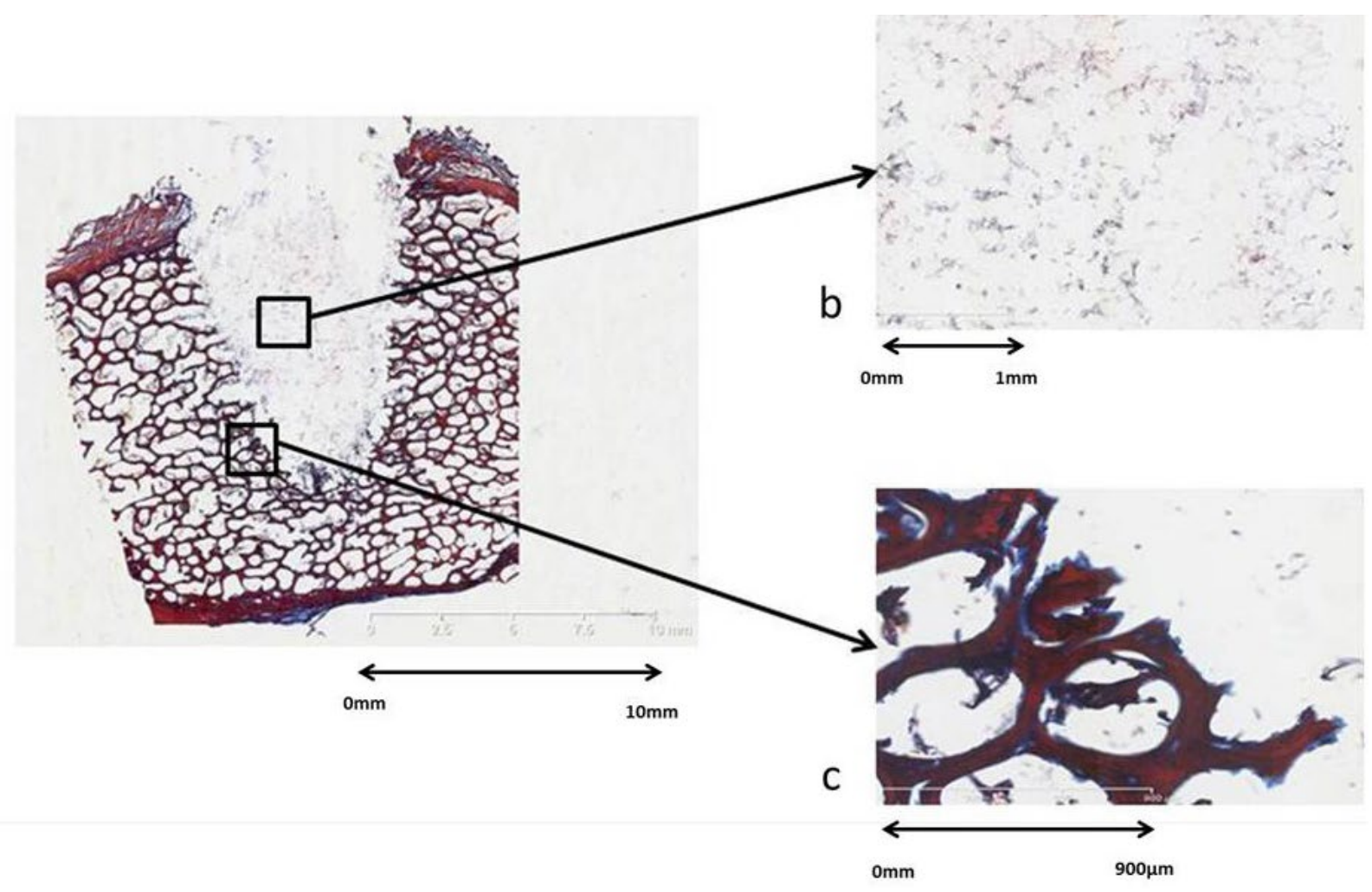

Fig. 10. Ralis tetrachrome staining within a bone defect in the femoral condyle of a control scaffold sheep sacrificed at 2 weeks (Group 3). Section b (originally, 2.5x magnification) shows the polymer remaining within the defect and $\mathrm{c}$ (originally, 5x magnification) shows areas of osteoid (dark blue) on the edges of the defect. 
Fig. 11. Image taken using a light microscope (originally, 5x magnificiation) of the centre of the defect containing polymer in a control scaffold sheep sacrificed at 2 weeks (Group 3).
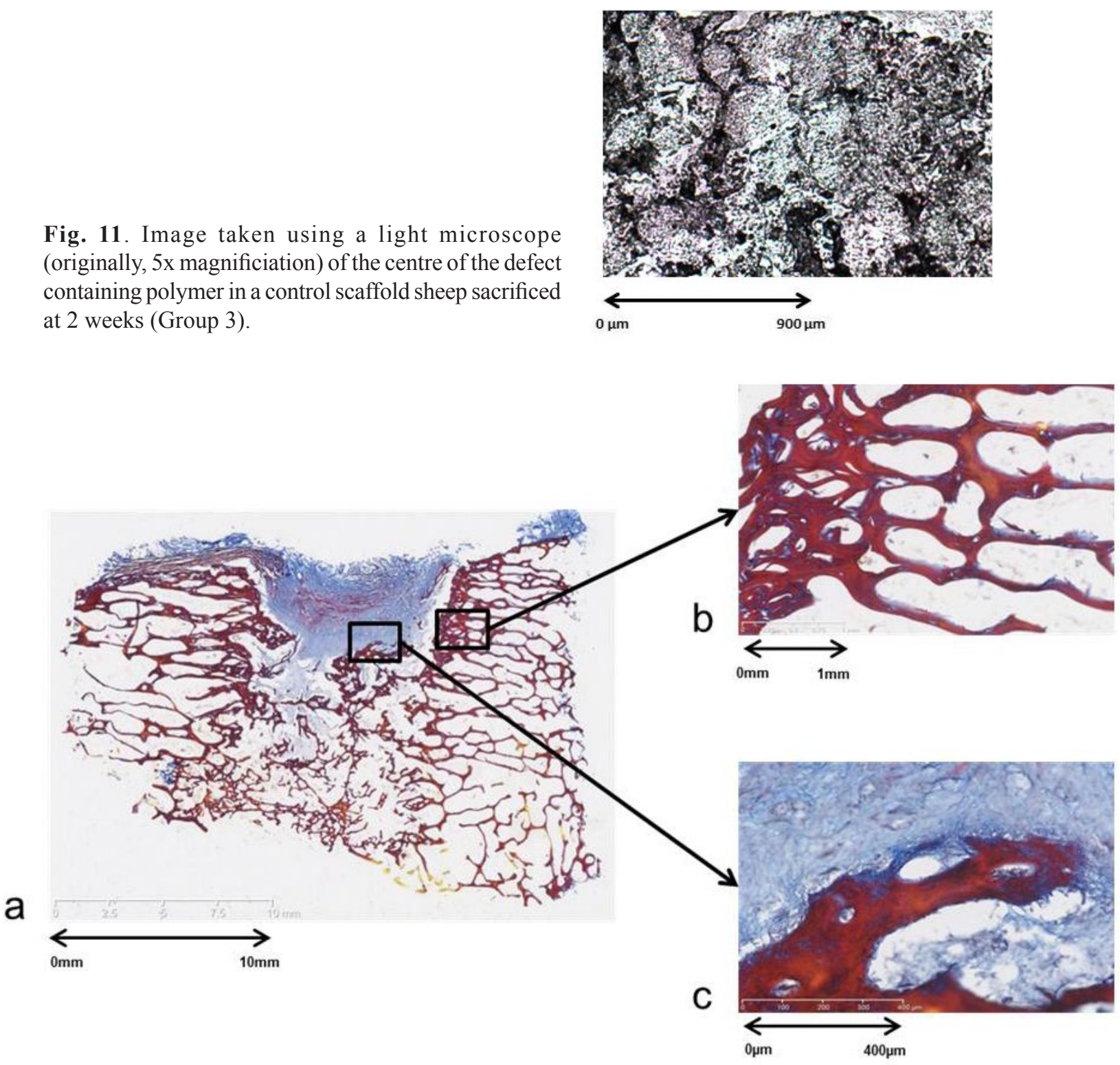

Fig. 12. Ralis tetrachrome staining demonstrating new bone ingrowth within a bone defect in the femoral condyle of a control scaffold sheep sacrificed at 13 weeks (Group 4). No scaffold material was remaining within the defect. Section $\mathrm{b}$ (originally, $2.5 \mathrm{x}$ magnification) shows the comparison of new and old bone and c (originally, 10x magnification) shows different areas of osteoid (dark blue), new bone (brown) and calcified cartilage (pink red).

control, Figs. 10 and 11). The edge of the defect was clearly visible with organised trabeculae, and scaffold material filling the majority of the defect. New bone could be seen forming at the edge of the defect. An osteoid layer was seen at the edges of the mature lamellar bone and at the mineralisation front.

Groups 4 (13 week scaffold control, Fig. 12) and 5 (13 week sacrifice with bacteria and antibiotic impregnated scaffold, Fig. 13).

No polymer was remaining within the defect at 13 weeks, and any area of the defect not filled with new bone contained soft tissue. The soft tissue was identified as cartilage that would be expected to eventually turn into mineralised bone. The edges of the original defect were clear and showed the different structures of new and old bone. At the interface of the new bone and soft tissue, there was a thick osteoid layer.

\section{Soft tissue histology}

Inflammatory cells, mainly macrophages, were observed in the soft tissue surrounding the defect site in all 5 groups as observed by others (Anderson and Shive, 2012).

\section{Discussion}

The biodegradable antibiotic-impregnated scaffold material was effective at preventing infection, whilst allowing new bone growth in a large animal bone defect model (8 mm diameter x $15 \mathrm{~mm}$ height).

The scaffold material described here showed a gradual release of antibiotics, with $50 \%$ of the antimicrobial activity present at Day 7 and $20 \%$ present at Day 15 as shown by SPTT (Fig. 2). It has been suggested that antibiotic concentration should be above the MIC for a 


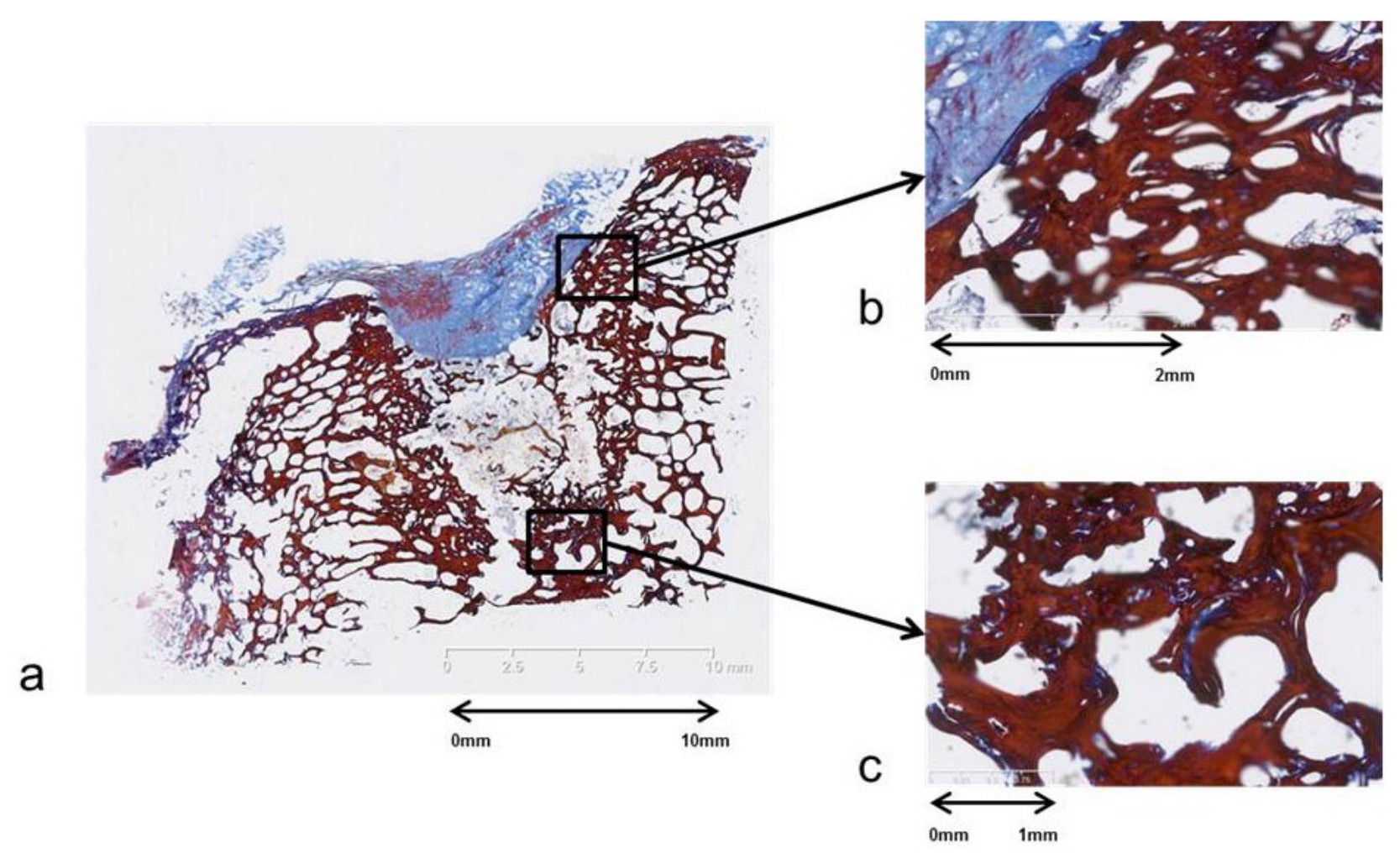

Fig. 13. Ralis tetrachrome staining demonstrating the new bone ingrowth in a bone defect in the femoral condyle of a sheep that received bacteria, antibiotic impregnated scaffold and was sacrificed at 13 weeks (Group 5). No scaffold material was remaining within the defect. The edges of the original defect are clear. Sections $b$ (originally, $1.25 \mathrm{x}$ magnification) and c (originally, 2.5x magnification) show different areas of osteoid (dark blue), new bone (brown) and calcified cartilage (pink red).

minimum of 7 days for effective prevention of infection (Campoccia et al., 2010). No zones of inhibition were seen after Day 21. Fracture of the remaining polymer and testing for zones of inhibition showed no residual activity (results not shown), indicating that if any antibiotics remained in the polymer they were below the MIC of the test bacteria. Previous work has shown that the release of antibiotics from non-biodegradable bone cements and beads peaks at Day 1 (Nandi et al., 2009), but continues to be released at sub-inhibitory levels for several months (Henry et al., 1991), with residual antibiotics found after 5 years in situ (Neut et al., 2003).

The antibiotics tested here were gentamicin sulphate and clindamycin hydrochloride, which are routinely used in the treatment of bone infection with cement spacers, due to their heat stability and hydrophilic nature (Gogia et al., 2009). Although systemic gentamicin sulphate has been shown to be potentially nephrotoxic and ototoxic (Smith et al., 1980), local delivery allows for significantly higher doses of the antibiotic to be delivered to the infected site, whilst avoiding the issue of systemic toxicity, when compared to the systemic administration of antibiotics (Gitelis and Brebach, 2002). The results shown here suggest that such an approach might be translatable into clinical practice, by preventing an infection starting and therefore reducing the use of long courses of systemic antibiotics required to treat infection with the concomitant risks of resistance and adverse effects.
A combination of antibiotics was used to further reduce the risk of resistance arising at the defect site. This approach has been shown to prevent resistance, as two concurrent mutations are required for bacterial survival when two antibiotics of different classes are each maintained at levels above their minimum inhibitory concentrations (Eliopoulos and Eliopoulos, 1988; Fantin and Carbon, 1992; Gould, 1999; Zhao and Drlica, 2001). The combination of gentamicin sulphate and clindamycin hydrochloride has been shown to have an antimicrobial effect on more than $90 \%$ of bacteria common to infected arthroplasties (Kuhn, 2000) and is more effective in preventing biofilm formation than bone cements with gentamicin alone (Neut et al., 2005). The combination can be expected to have activity against gram-positive bacteria (e.g. staphylococci), gram-negative bacteria (e.g. Escherichia coli) and anaerobes (e.g. Bacteroides spp).

The addition of the antibiotic combination did not significantly affect the compressive strength or the porosity of the material. Unlike the material investigated in this study, there is a large variation in the mechanical properties of bone cements after the addition of antibiotics (Dall et al., 2007; Lewis, 2008; Hsieh et al., 2009). Porosity is determined by the method of mixing, which has a significant effect on the rate of antibiotic release (Neut et al., 2007; Web Ref. 4).

Bone defects in groups 1, 2 and 4 were inoculated with $20 \mu \mathrm{L}$ of $2 \times 10^{6} \mathrm{cfu} / \mathrm{mL}$ of $S$. aureus, using a method 
described by Beardmore et al. (2005). All sheep that were inoculated with $S$. aureus and did not receive antibiotics within the scaffold material showed clinical signs of a localised bone infection, and bone lysis was observed on the micro-CT images. At sacrifice, the same strain of $S$. aureus was cultured from samples collected from within the defect and surrounding tissue. Therefore, with the addition of antibiotics to the material it was possible to prevent bone infection. Although $S$. aureus is the most common isolate, a range of different bacteria can cause bone infection (Mader et al., 1999). As this study investigated the efficacy of the scaffold material only against $S$. aureus, further investigations are needed to determine the activity of the material when challenged by other bacteria or by more than one species at the same time.

By 13 weeks the bone defects drilled in experimental or control femoral condyles and packed with the scaffold either with or without antibiotics, were over $60 \%$ full. The scaffold material had fully degraded at 13 weeks, as was seen by Schmidt et al. (1995) in the subcutaneous pouches of rats. Ideally, the degradation rate of bone graft material should match the rate of the bone growth (Vaccaro, 2002; Wenisch et al., 2003).

PLGA degrades into lactic acid and glycolic acid, which are removed by the body's normal metabolic pathways (Wu and Ding, 2004). The degradation products reduce the $\mathrm{pH}$ in the vicinity of the scaffold material ( $\mathrm{Li}$ and Chang, 2005) and this can result in an inflammatory response. This is often clinically insignificant, and less likely to arise with porous implants as degradation products do not accumulate as readily (Ambrose and Clanton, 2004). An inflammatory response was observed in soft tissue collected from around the defect site in all groups. Macrophages attracted by the presence of a foreign body can mediate the biodegradation of the materials by phagocytosis (Xia and Triffitt, 2006; Anderson and Shive, 2012) and are also essential for effective tissue regeneration as they clear cellular debris and encourage the growth of blood vessels and therefore restore a vital blood supply.

Bone ingrowth is thought to be directly linked to porosity and pore size (Feng et al., 2011). Porosity of the scaffold material in vivo, both with and without antibiotics, was approximately $25 \%$ with pore sizes ranging from 162-222 $\mu \mathrm{m}$ and therefore within the published osteoconductive range (von Doernberg et al., 2006; Bignon et al., 2011), although pore sizes of greater than $300 \mu \mathrm{m}$ are thought to allow greater penetration of mineralised tissue (Jones et al., 2004). Microporosity (pores $\leq 5 \mu \mathrm{m}$ ) has been shown to be essential for the bioresorbability of the material, whilst macroporosity (pores $\geq 100 \mu \mathrm{m}$ ) is involved in osteoconductivity (Hannink and Arts, 2011). Larger pores facilitate enhanced bioactivity but reduce PLGA/PEG bridging points per unit area and in turn mechanical strength (Karageorgiou and Kaplan, 2005). A high pore volume facilitates the circulation of body fluids and therefore increases the potential for the firm attachment of new bone tissue (Blokhuis et al., 2000). The interconnectivity of pores has also been shown to have a significant effect on bone growth within a scaffold material (Lu et al., 1999), but was not investigated in this study.
New bone ingrowth into the defects of sheep sacrificed at 13 weeks showed no significant difference, suggesting that there was no inhibitory effect of the antibiotic combination on osteogenesis. An osteoid layer was seen at the edges of the mineralised bone and where new immature bone was forming. A fibrous collagen plug had filled the top portion of the defect, and this was becoming calcified and in time may have become mineralised bone (Shearer et al., 1992). A review of current literature by Pountos et al. (2011) suggested that although there is evidence that antibiotics inhibit cell proliferation in vitro (Gogia et al., 2009), in vivo fracture healing is not impaired (Haleem et al., 2004), as was shown in this study.

Unlike this study, the majority of the literature describes the treatment of infection, not its prevention, and the use of materials that are either non-biodegradable, contain only one antibiotic or do not support bone growth (van der Stok et al., 2010; El-Husseiny et al., 2011). PLGA and PLA have been used in several studies that have been successful in treating infection (Garvin et al., 1994; Kanellakopoulou et al., 2000; Liu et al., 2002; Ambrose et al., 2004; Koort et al., 2005; Peng et al., 2010; Ambrose et al., 2014), but only a single antibiotic has been tested. The use of hydroxyapatite (Korkusuz et al., 1993; Shinto et al., 1992; Itokazu et al., 1997), calcium phosphate (Nandi et al., 2008) and calcium sulphate (Turner et al., 2005; Parker et al., 2011) in combination with one antibiotic have also been shown to treat infection.

Although this study was designed to test the efficacy of the antibiotic impregnated material at preventing infection a limitation of this study was the omission of a positive (autologous bone graft) and negative control (empty defect). This would have allowed us to prove that the bone ingrowth seen was truly due to the presence of the scaffold material. The only published reference of an empty defect (5 mm diameter x $15 \mathrm{~mm}$ height) in the sheep femoral condyle model stated that an empty defect contained $26.9 \pm 6.4 \%$ at 4 months (van der Pol et al., 2010).

\section{Conclusions}

We have shown that a gradual release of a combination of antibiotics over 19-21 days is achievable in vitro from a biodegradable scaffold, without any negative effects on the mechanical properties of the scaffold. We have further shown that the antimicrobial material was able to prevent $S$. aureus infection from establishing in bone defects in sheep, whilst supporting a significant amount of new bone growth in a 13 week period. Further research is being carried out to demonstrate the activity of the biodegradable antimicrobial polymer against a wider range of bacteria, which in turn may allow the material to be used in the earlier treatment of traumatic bone loss with the reduction of infective complications, possibly removing the need for concurrent systemic therapy, thus reducing adverse events and bacterial resistance. 


\section{Acknowledgements}

This project was funded by the Medical Research Council Developmental Pathway Funding Scheme. The authors would like to thank Gillian Hughes for her invaluable help with the animal study, Sharon Crouch and Alan Burbidge for their guidance and Denise Christie, Emma King and Marie Smith for their assistance in the histological method development. KMS received an ERC Advanced Grant.

\section{References}

Ambrose CG, Clanton O (2004) Bioabsorbable implants: review of clinical experience in orthopedic surgery. Ann Biomed Eng 32: 171-177.

Ambrose CG, Clyburn TA, Louden K, Joseph J, Wright J, Gulati P, Gogola GR, Mikos AG (2004) Effective treatment of osteomyelitis with biodegradable microspheres in a rabbit model. Clin Orthop Rel Res 421: 293-299.

Ambrose CG, Clyburn TA, Mika M, Gogola GR, Kaplan HB, Wanger A, Mikos AG (2014) Evaluation of antibiotic-impregnated microspheres for the prevention of implant-associated orthopaedic infections. J Bone Joint Surg Am 96: 128-134.

Anderson JM, Shive MS (1997) Biodegradation and biocompatibility of PLA and PLGA microspheres. Adv Drug Deliver Rev 28: 5-24.

Anderson JM, Shive MS (2012) Biodegradation and biocompatibility of PLA and PLGA microspheres. Adv Drug Deliver Rev 64: 72-82.

Bayston R, Fisher LE, Weber K (2009) An antimicrobial modified silicone peritoneal catheter with activity against both Gram-positive and Gram-negative bacteria. Biomater 30: $3167-3173$.

Beardmore AA, Brooks DE, Wenke JC, Thomas DB (2005) Effectiveness of local antibiotic delivery with an osteoinductive and osteoconductive bone-graft substitute. J Bone Joint Surg 87A: 107-112.

Bignon A, Chouteau J, Chevalier J, Fantozzi G, Carret JP, Chavassieux P, Boivin G, Melin M, Hartmann D (2003) Effect of micro- and macroporosity of bone substitutes on their mechanical properties and cellular response. J Mater Sci-Mater Med 14: 1089-1097.

Blokhuis TJ, Termaat MF, den Boer FC, Patka P, Bakker FC, Haarman HJTM (2000) Properties of calcium phosphate ceramics in relation to their in vivo behavior. J Trauma 48: 179-186.

Bodde EWH, Wolke JGC, Kowalski RSZ, Jansen JA (2007) Bone regeneration of porous $\beta$-tricalcium phosphate (Conduit ${ }^{\mathrm{TM}}$ TCP) and of biphasic calcium phosphate ceramic $\left(\right.$ Biosel $\left.^{\circledR}\right)$ in trabecular defects in sheep. J Biomed Mater Res A 82A: 711-722.

Campoccia D, Montanaro L, Speziale P, Arciola CR (2010) Antibiotic-loaded biomaterials and the risks for the spread of antibiotic resistance following their prophylactic and therapeutic clinical use. Biomaterials 31: 6363-6377.

Carson JS, Bostrom MP (2007) Synthetic bone scaffolds and fracture repair. Injury 38 Suppl 1: S33-37.
Dall GF, Simpson PMS, Mackenzie SP, Breusch SJ (2007) Inter- and intra-batch variability in the handling characteristics and viscosity of commonly used antibioticloaded bone cements. Acta Orthop 78: 412-420.

Dhillon A, Schneider P, Kuhn G, Reinwald Y, White LJ, Levchuk A, Rose FRAJ, Muller R, Shakesheff KM, Rahman CV (2011) Analysis of sintered polymer scaffolds using concomitant synchrotron computed tomography and in situ mechanical testing. J Mater Sci-Mater Med 22: 2599-2605.

Ding M, Røjskjær J, Cheng L, Theilgaard N, Overgaard S (2012) The effects of a novel-reinforced bone substitute and Colloss ${ }^{\circledR} \mathrm{E}$ on bone defect healing in sheep. J Biomed Mater Res Part B 100B:1826-1835.

El-Husseiny M, Patel S, MacFarlane RJ, Haddad FS (2011) Biodegradable antibiotic

delivery systems. J Bone Joint Surg 93B: 151-157.

Eliopoulos GM, Eliopoulos CT (1988) Antibiotic combinations: should they be tested? Clin Microbiol Rev 1: 139-156.

Fantin B, Carbon C (1992) In vivo antibiotic synergism - contribution of animal-models. Antimicrob Ag Chemother 36: 907-912.

Feng B, Jinkang Z, Zhen W, Jianxi L, Jiang C, Jian L, Guolin M, Xin D (2011) The effect of pore size on tissue ingrowth and neovascularization in porous bioceramics of controlled architecture in vivo. Biomed Mater 6015007.

France R, Quirk R A (2008) Porous Matrix. US Patent Number 0241248.

Garvin KL, Miyano JA, Robinson D, Giger D, Novak J, Radio S (1994) Polylactide/polyglycolide antibiotic implants in the treatment of osteomyelitis - a canine model. J Bone Joint Surg 76A: 1500-1506.

Giannoudis PV, Papakostidis C, Roberts C (2006) A review of the management of open fractures of the tibia and femur. J Bone Joint Surg 88B: 281-289.

Ginty PJ, Barry JJ, White LJ, Howdle SM, Shakesheff KM (2008) Controlling protein release from scaffolds using polymer blends and composites. Eur J Pharm Biopharm 68: $82-89$.

Gitelis S, Brebach GT (2002) The treatment of chronic osteomyelitis with a biodegradable antibiotic-impregnated implant. J Orthop Surg (Hong Kong) 10: 53-60.

Gogia JS, Meehan JP, Di Cesare PE, Jamali AA (2009) Local antibiotic therapy in osteomyelitis. Semin Plast Surg 23: 100-107.

Gould IM (1999) A review of the role of antibiotic policies in the control of antibiotic resistance. J Antimicrob Chemother 43: 459-465.

Gould TWA, Birchall JP, Mallick AS, Alliston T, Lustig LR, Shakesheff KM, Rahman CV (2013) Development of a porous poly(DL-lactic acid-co-glycolic acid)-based scaffold for mastoid air-cell regeneration. Laryngoscope 123: 3156-3161.

Haleem AA, Rouse MS, Lewallen DG, Hanssen AD, Steckelberg JM, Patel R (2004) Gentamicin and vancomycin do not impair experimental fracture healing. Clin Orthop Rel Res 427: 22-24.

Hannink G, Arts JJ (2011) Bioresorbability, porosity and mechanical strength of bone substitutes: what is optimal for bone regeneration? Injury 42 Suppl 2: S22-25. 
Henry SL, Seligson D, Mangino P, Popham GJ (1991) Antibiotic-impregnated beads. Part I: Bead implantation versus systemic therapy. Orthop Rev 20: 242-247.

Hing KA, Wilson LF, Buckland T (2007) Comparative performance of three ceramic bone graft substitutes. Spine J 7: 475-490.

Hsieh PH, Tai CL, Lee PC, Chang YH (2009) Liquid gentamicin and vancomycin in bone cement: a potentially more cost-effective regimen. J Arthroplasty 24: 125-130.

Ilan DI, Ladd AL (2003) Bone graft substitutes. Operat Tech Plas Reconstr Surg 9: 151-160.

Itokazu M, Ohno T, Tanemori T, Wada E, Kato N, Watanabe K (1997) Antibiotic-loaded hydroxyapatite blocks in the treatment of experimental osteomyelitis in rats. J Med Microbiol 46: 779-783.

Jacobsen S, Fritz HG (1999) Plasticizing polylactide - The effect of different plasticizers on the mechanical properties. Polym Eng Sci 39: 1303-1310.

Jones AC, Milthorpe B, Averdunk H, Limaye A, Senden TJ, Sakellariou A, Sheppard AP, Sok RM, Knackstedt MA, Brandwood A, Rohner D, Hutmacher DW (2004) Analysis of 3D bone ingrowth into polymer scaffolds via micro-computed tomography imaging. Biomaterials 25: 4947-4954.

Kanellakopoulou K, Galanakis N, GiamarellosBourboulis EJ, Rifiotis C, Papakostas K, Andreopoulos A, Dounis E, Karagianakos P, Giamarellou H (2000) Treatment of experimental osteomyelitis caused by methicillin-resistant Staphylococcus aureus with a biodegradable system of lactic acid polymer releasing pefloxacin. J Antimicrob Chemother 46: 311-314.

Karageorgiou V, Kaplan D (2005) Porosity of 3D biomaterial scaffolds and osteogenesis. Biomaterials 26: 5474-5491.

Kirby GTS, White LJ, Rahman CV, Cox HC, Qutachi O, Rose FRAJ, Hutmacher DW, Shakesheff KM, Woodruff MA (2011) PLGA-Based microparticles for the sustained release of BMP-2. Polymers 3: 571-586.

Koort JK, Makinen TJ, Suokas E, Veiranto M, Jalava J, Knuuti J, Tormala P, Aro HT (2005) Efficacy of ciprofloxacin-releasing bioabsorbable osteoconductive bone defect filter for treatment of experimental osteomyelitis due to Staphylococcus aureus. Antimicrob Ag Chemother 49: 1502-1508.

Korkusuz F, Uchida A, Shinto Y, Araki N, Inoue K, Ono K (1993) Experimental implant-related osteomyelitis treated by antibiotic-calcium hydroxyapatite ceramic composites. J Bone Joint Surg 75: 111-114.

Kuhn KD (2000) Further comparative studies. In: Bone Cements: Up-To-Date Comparison of Physical and Chemical Properties of Commercial Materials. SpringerVerlag Berlin, pp 233-262.

Lee SH, Shin H (2007) Matrices and scaffolds for delivery of bioactive molecules in bone and cartilage tissue engineering. Adv Drug Deliver Rev 59: 339-359.

Lewis G (2008) Alternative acrylic bone cement formulations for cemented arthroplasties: Present status, key issues, and future prospects. J Biomed Mater Res B-Appl Biomater 84B: 301-319.
Li H, Chang J (2005) pH-compensation effect of bioactive inorganic fillers on the degradation of PLGA. Compos Sci Technol 65: 2226-2232.

Liu SJ, Ueng SWN, Lin SS, Chan EC (2002) In vivo release of vancomycin from biodegradable beads. J Biomed Mater Res A 63: 807-813.

Lu JX, Flautre B, Anselme K, Hardouin P, Gallur A, Descamps M, Thierry B (1999) Role of interconnections in porous bioceramics on bone recolonization in vitro and in vivo. J Mater Sci-Mater Med 10: 111-120.

Mader JT, Shirtliff ME, Bergquist SC, Calhoun J (1999) Antimicrobial treatment of chronic osteomyelitis. Clin Orthop Rel Res 360: 47-65.

Martini L, Fini M, Giavaresi G, Giardino R (2001) Sheep model in orthopedic research: A literature review. Comparative Med 51: 292-299.

Mastrogiacomo M, Scaglione S, Martinetti R, Dolcini L, Beltrame F, Cancedda R, Quarto R (2006) Role of scaffold internal structure on in vivo bone formation in macroporous calcium phosphate bioceramics. Biomaterials 27: 3230-3237.

Motsitsi NS (2008) Management of infected nonunion of long bones: the last decade (1996-2006). Injury 39: 155160 .

Nandi SK, Ghosh SK, Kundu B, De DK, Basu D (2008) Evaluation of new porous beta-tri-calcium phosphate ceramic as bone substitute in goat model. Small Ruminant Res 75: 144-153.

Nandi SK, Mukherjee P, Roy S, Kundu B, De DK, Basu D (2009) Local antibiotic delivery systems for the treatment of osteomyelitis -A review. Mater Sci Eng: C29: 2478-2485.

Neut D, de Groot EP, Kowalski RS, van Horn JR, van der Mei HC, Busscher HJ (2005) Gentamicin-loaded bone cement with clindamycin or fusidic acid added: biofilm formation and antibiotic release. J Biomed Mater Res A 73A: $165-170$.

Neut D, van de Belt H, van Horn JR, van der Mei HC, Busscher HJ (2003) Residual gentamicin-release from antibiotic-loaded polymethylmethacrylate beads after 5 years of implantation. Biomaterials 24: 1829-1831.

Neut D, van der Mei HC, Bulstra SK, Busscher HJ (2007) The role of small-colony variants in failure to diagnose and treat biofilm infections in orthopedics. Acta Orthop 78: 299-308.

Nuss KM, Auer JA, Boos A, Von Rechenberg B (2006) An animal model in sheep for biocompatibility testing of biomaterials in cancellous bones. BMC Musculoskelet Disord 7: 67.

Ostermann PAW, Seligson D, Henry SL (1995) Local antibiotic-therapy for severe open fractures - a review of 1085 consecutive cases. J Bone Joint Surg 77B: 93-97.

Parker AC, Smith JK, Courtney HS, Haggard WO (2011) Evaluation of two sources of calcium sulfate for a local drug delivery system: a pilot study. Clin Orthop Relat Res 469: 3008-3015.

Patel N, Brooks RA, Clarke MT, Lee PMT, Rushton N, Gibson IR, Best SM, Bonfield W (2005) In vivo assessment of hydroxyapatite and silicate-substituted hydroxyapatite 
granules using an ovine model. J Mater Sci-Mater Med 16: 429-440.

Patzakis MJ, Wilkins J (1989) Factors influencing infection-rate in open fracture wounds. Clin Orthop Rel Res 243: 36-40.

Pearce AI, Richards RG, Milz S, Schneider E, Pearce SG (2007) Animal models for implant biomaterial research in bone: A review. Eur Cells Mater 13: 1-10.

Peng K, Chen C, Chu I, Li Y, Hsu W, Hsu R, Chang P (2010) Treatment of osteomyelitis with teicoplaninencapsulated biodegradable thermosensitive hydrogel particles. Biomater 31: 5227-5236.

Pountos I, Georgouli T, Bird H, Kontakis G, Giannoudis PV (2011) The effect of antibiotics on bone healing: current evidence. Expert Opin Drug Saf 10: 935-945.

Ralis ZA, Watkins G (1992) Modified tetrachrome method for osteoid and defectively mineralized bone in paraffin sections. Biotech Histochem 67: 339-345.

Rahman CV, Smith SJ, Morgan PS, Langmack KA, Clarke PA, Ritchie AA, Macarthur DC, Rose FR, Shakesheff KM, Grundy RG, Rahman R (2013) Adjuvant chemotherapy for brain tumors delivered via a novel intracavity moldable polymer matrix. PLoS ONE 8: e77435.

Rahman CV, Ben-David D, Dhillon A, Kuhn G, Gould TWA, Müller R, Rose FRAJ, Shakesheff KM, Livne E (2014) Controlled release of BMP-2 from a sintered polymer scaffold enhances bone repair in a mouse calvarial defect model. J Tissue Eng Regen Med. 8: 59-66.

Schmidt C, Wenz R, Nies B, Moll F (1995) Antibiotic in vivo in vitro release, histocompatibility and biodegradation of gentamicin implants based on lactic-acid polymers and copolymers. J Control Release 37: 83-94.

Shearer JR, Roach HI, Parsons SW (1992) Histology of a lengthened human tibia. J Bone Joint Surg 74B: 39-44.

Shinto Y, Uchida A, Korkusuz F, Araki N, Ono K (1992) Calcium hydroxyapatite ceramic used as a delivery system for antibiotics. J Bone Joint Surg 74B: 600-604.

Smith CR, Lipsky JJ, Laskin OL, Hellmann DB, Mellits ED, Longstreth J, Lietman PS (1980) Double-blind comparison of the nephrotoxicity and auditory toxicity of gentamicin and tobramycin. N Eng J Med 302: 1106-1109.

Stanczyk M, van Rietbergen B (2004) Thermal analysis of bone cement polymerisation at the cement-bone interface. J Biomech 37: 1803-1810.

Turner TM, Urban RM, Hall DJ, Chye PC, Segreti J, Gitelis S (2005) Local and systemic levels of tobramycin delivered from calcium sulfate bone graft substitute pellets. Clin Orthop Rel Res 437: 97-104.

Vaccaro AR (2002) The role of the osteoconductive scaffold in synthetic bone graft. Orthopedics 25: S571-S578.

van der Pol U, Mathieu L, Zeiter S, Bourban P-E, Zambelli P-Y, Pearce SG, Bouré LP, Pioletti DP (2010) Augmentation of bone defect healing using a new biocomposite scaffold: An in vivo study in sheep. Acta Biomater 6: 3755-3762.

van der Stok J, van Lieshout EM, El-Massoudi Y, van Kralingen GH, Patka P (2011) Bone substitutes in the Netherlands - a systematic literature review. Acta Biomater 7: 739-750. von Doernberg MC, von Rechenberg B, Bohner M, Grunenfelder S, van Lenthe GH, Muller R, Gasser B, Mathys R, Baroud G, Auer J (2006) In vivo behavior of calcium phosphate scaffolds with four different pore sizes. Biomater 27: 5186-5198.

Wenisch S, Stahl JP, Horas U, Heiss C, Kilian O, Trinkaus K, Hild A, Schnettler R (2003) In vivo mechanisms of hydroxyapatite ceramic degradation by osteoclasts: Fine structural microscopy. J Biomed Mater Res A 67A: 713-718.

Walsh WR, Morberg P, Yu Y, Yang JL, Haggard W, Sheath PC, Svehla M, Bruce WJM (2003) Response of a calcium sulfate bone graft substitute in a confined cancellous defect. Clin Orthop Rel Res 406: 228-236.

Wu LB, Ding JD (2004) In vitro degradation of three-dimensional porous poly(D,L-lactide-co-glycolide) scaffolds for tissue engineering. Biomater 25: 5821-5830.

Xia Z, Triffitt JT (2006) A review on macrophage responses to biomaterials. Biomed Mater 1: R1-9.

Zalavras CG, Marcus RE, Levin LS, Patzakis MJ (2007) Management of open fractures and subsequent complications. J Bone Joint Surg 89A: 884-895.

Zhao XL, Drlica K (2001) Restricting the selection of antibiotic-resistant mutants: A general strategy derived from fluoroquinolone studies. Clin Infect Dis 33: S147-S156.

Zhao XL, Drlica K (2002) Restricting the selection of antibiotic-resistant mutant bacteria: Measurement and potential use of the mutant selection window. J Infect Dis 185: 561-565.

Zolnik BS, Burgess DJ (2007) Effect of acidic pH on PLGA microsphere degradation and release. J Control Release 122: 338-344.

\section{Web References}

Web Ref. 1 British National Formulary. Number 62. 2011: Section 5.1.4. Available from URL: http://www. medicinescomplete.com/mc/bnf/current/3831.htm [07-112012].

Web Ref. 2 British Society for Antimicrobial Chemotherapy. Methods for Antimicrobial Susceptibility Testing 2012; Version 11.1. Online. 2012. Available from URL: http://bsac.org.uk/wp-content/uploads/2012/02/ Version-11.1-2012-Final-.pdf [07-11-2012].

Web Ref. 3 Guidance on the Operation of Animals (Scientific Procedures) Act 1986. Online. 2000. Available from URL: http://www.official-documents.gov.uk/ document/hc9900/hc03/0321/0321.pdf [07-11-2012].

Web Ref. 4 Clyburn TAC, Cui Q. Antibiotic laden cement: current state of the art. AAOS Now 2011. Available from URL: http://www.aaos.org/news/bulletin/may07/ clinical7.asp [07-11-2012].

\section{Discussion with Reviewers}

T. Moriarty: How is the effective duration of in vivo antibiotic dosing (stated to be 7 days; Campoccia et al., 2010 , text reference) to prevent clinical surgical infection 
determined since this value seems to be highly variable in the literature?

Authors: The length of duration is highly variable as there is no evidence in the literature to support a particular timescale. For surgical prophylaxis in clean implants $24 \mathrm{~h}$ of antibiotic cover has been shown to be adequate. However as we are aiming to prevent infection at a more contaminated site in this study it was felt that 7 days would be suitable. This was confirmed as an effective duration as all sheep that were infected with $S$. aureus and received the antibiotic impregnated scaffold material were found to be free of infection at the 2 week and 13 week sacrifice time points.

T. Moriarty: Must local osteocyte or osteoblast toxicity to drug release be determined in vivo in the wound site to ascertain safety? How might local pharmacology be assessed?

Authors: There are a range of tests required according to the International Standard ISO 10993: Biological Evaluation of Medical Devices (Web Ref. D1, additional reference). Both cytotoxicity and mutagenicity (ISO 10993:3) have been carried out on the antibiotic free product, and was found to be both non-mutagenic and noncytotoxic. Endotoxin testing (ISO 10993:11) has not yet been carried out on the product with or without antibiotics, but will be carried out during future pre-clinical studies.

Draft guidance was released by the FDA on antimicrobial devices (Web Ref. D2, additional reference). This stated a range of tests that should be carried out during pre-clinical testing. These include: the identity and formulation of antimicrobial agents and accompanying substances; concentration of the antimicrobial agent on the device; method used to apply the antimicrobial agent to the device; mechanism of action of the agent; antimicrobial activity spectrum of the agent; release kinetics of the agent from the device over time; minimum effective concentration; and toxicity of the agent.

Local pharmacology could be assessed by collecting bone, blood and soft tissue samples, both locally and systemically, and processing them to be analysed on an HPLC to detect the levels of the antibiotics at different time points. Recommended methods are published in the British Pharmacopeia (Web Ref. D3, additional reference) and in ASTM International (Web Ref. D4, additional reference).

T. Moriarty: How do regulatory bodies view the dual antibiotic release strategy? Is there an approval route seen that would allow this strategy to move forward for clinical adoption?

Authors: A regulatory strategy has been created after meeting with regulatory consultants. The device is classed as a combinational product due to the use of two pharmacological registered antibiotics. In the US it will be classed by the FDA as a Class III device and in Europe by the MHRA as a Class III device.

For both the FDA and the MHRA the recommended bench testing includes in vitro studies to demonstrate the effectiveness of the device with relevant clinical isolates to show the spectrum and activity of the antibiotics on the medical device. The studies must include a comparison of the antibiotic impregnated device with the device alone, and establish the relationship between the antibiotic effectiveness and the effective concentration of the antibiotics in the device. Studies must also be carried out to look at the elution of the antibiotic over time. In addition, it is recommended to conduct tests to assess the antibiotic's effect on the specifications or performance of the device. This would include an assessment of material or surface changes, and changes to device integrity, stability, and mechanical durability.

European registration will require a design dossier covering both the device element and the medicinal element. The device element would be assessed by an assigned notified body, and the medicinal element would be reviewed by the MHRA in the UK. This file would be reviewed by a notified body as it is a new pharmaceutical application. Clinical evidence will be required for both elements, which will involve a formal trial due to two antibiotics being used in combination.

Registration in the USA will require Premarket Approval (PMA) as it is a Class III device and would be under the jurisdiction of the Office of Combination Products (OCP). PMA is the most stringent type of device marketing application required by the FDA and would take 180 days to review.

T. Moriarty: Does sterilisation method affect 1) material degradation characteristics, 2) drug potency?

Authors: The method of sterilisation was electron beam sterilisation at 25-30 kGy. Published literature states that there are several effects of ionising radiation on PLGA, although electron beam sterilisation has been reported to be less damaging than gamma sterilisation (Nuutinen et al., 2002, additional reference). This damage can be a drop in the molecular weight and glass transition temperature, a loss in the mechanical properties and an increased rate in degradation (Loo et al., 2005, additional reference). Tests were carried out by the industrial partner, and do show that there is a small effect of electron beam sterilisation on the scaffold material. The molecular weight, assessed by Gel Permeation Chromatography, is approximately $6 \%$ lower after sterilisation. Previous work carried out implanting the same electron beam sterilised scaffold material in the calvarial defect of a mouse was successful at encouraging bone growth, suggesting no deleterious effects of sterilisation (Rahman et al., 2012, text reference). Further investigations will be carried out to look at the degradation rate.

In this study, the drug bioavailability would not have been affected by sterilisation as the antibiotics were mixed with the product after suspension in an autoclaved solution of $\mathrm{CMC}$, and did not undergo electron beam sterilisation. Ionising radiation is routinely used to sterilise antibiotic containing bone cements (Web Ref. D5, additional reference) although literature has shown that there may be some effects on the degradation and the antimicrobial activity of antibiotics, however a dry powder may show less of an effect than an aqueous solution (Abuhanoğlu and Özer, 2010, additional reference). 
Reviewer III: When do you expect the entire release of the antibiotics from the scaffold? Even if no Zone of inhibition is formed after 19 days, this does not mean that the scaffold is free of Abx.

Authors: Fracture of the remaining polymer and testing for zones of inhibition showed no residual activity indicating that if any antibiotics remained in the polymer that they were below the MIC of the test bacteria. If there were any antibiotics trapped within the scaffold material, this study has shown that the scaffold material biodegrades before 13 weeks, and is therefore free of antibiotics at that point. In addition, tests could be run on in vitro scaffolds at several time points to assess the antibiotic content.

\section{Additional References}

Abuhanoğlu G, Özer AY (2010) Radiation effects on pharmaceuticals. FABAD J Pharm Sci 35: 203-217.

Loo JSC, Ooi CP, Boey FYC (2005) Degradation of poly(lactide-co-glycolide) (PLGA) and poly(L-lactide) (PLLA) by electron beam radiation. Biomaterials 26: 1359-1367.

Nuutinen J, Clerc C, Virta T, Törmälä P (2002) Effect of gamma, ethylene oxide, electron beam and plasma sterilisation on the behaviour of SR-PLLA fibres in vitro. J Biomater Sci Polymer Edn 12: 1325-1336.

\section{Additional Web References}

Web Ref. D1 International Standard ISO 10993 Parts 1-18 (2003) Biological evaluation of medical devices. Available from URL: http://www.iso.org/iso/home/store/ catalogue_tc/catalogue_detail.htm?csnumber=44908 [1405-2013].

Web Ref. D2 Draft Guidance for Industry and FDA Staff. Premarket Notification [510(k)] Submissions for Medical Devices that include antimicrobial agents. Available from URL: http://www.fda.gov/OHRMS/ DOCKETS/98fr/07d-0201-gdl0001.pdf [14-05-2013].

Web Ref. D3 British Pharmacopeia. Available from URL: http://www.pharmacopoeia.co.uk/ [14-05-2013].

Web Ref. D4 ASTM International Standards. Available from URL: http://www.astm.org/Standard/index.shtml [14-05-2013].

Web Ref. D5 DePuy CMW Orthopaedic Gentamicin Bone Cements. Available from URL: https://www. jnjgatewayifu.com/eLabelingContent/Dpo/USENG/ CMWeifu001_84324.pdf

[14-05-2013]. 